\title{
LA NARCOTIZACIÓN DEL ACTIVISMO GUERRILLERO DE LAS FARC Y EL ELN 1998-2012
}

\author{
Jerónimo Ríos Sierra ${ }^{1}$ \\ Universidad EAN, Bogotá
}

\begin{abstract}
Resumen:
El artículo que se presenta tiene como propósito plantear hasta qué punto, durante los últimos años, con motivo de las políticas de seguridad, especialmente, de Andrés Pastrana (19982002) y Álvaro Uribe (2002-2010), las guerrillas de las FARC y del ELN han experimentado un importante proceso de transformación. Lo anterior, por el cambio en las dinámicas espaciales del conflicto armado, que ha tendido a concentrarse en enclaves periféricos, de índole fronteriza, pero, sobre todo, caracterizados por una mayor dependencia de las finanzas provenientes del cultivo ilícito. Esto termina por desnaturalizar a las guerrillas y favorecer la posibilidad de entender las nuevas dinámicas de la violencia en Colombia así como las opciones reales de superación del conflicto.
\end{abstract}

Palabras clave: Conflicto armado, Colombia, Narcotización, FARC, ELN.

Titulo en Inglés: “The Narcotisation of FARC and ELN guerilla activities, 1998-2012”

\section{Abstract:}

This article aims to present the security policies implemented by Andrés Pastrana (19982002) and Alvaro Uribe (2002-2010) and how these policies transformed the FARC and ELN guerrillas, taking into consideration the change in the spatial dynamics of the armed conflict, which has increasingly focused on peripheral and border enclaves and the increased reliance of funds coming from illicit crops. All this ended up distorting the guerrillas and enhances the ability to understand the new dynamics of violence in Colombia and the real options for overcoming the conflict.

Keywords: Armed Conflict.Colombia,Narcotisation, FARC, ELN.

\section{Copyright (C) UNISCI, 2016.}

Las opiniones expresadas en estos artículos son propias de sus autores, y no reflejan necesariamente la opinión de UNISCI. The views expressed in these articles are those of the authors, and do not necessarily reflect the views of UNISCI

\footnotetext{
${ }^{1}$ Jerónimo Ríos Sierra es Profesor de Estudios Internacionales de la Facultad de Administración, Finanzas y Ciencias Económicas de la Universidad EAN, Bogotá.

Email: jriossie@ean.edu.co.

DOI: http://dx.doi.org/10.5209/rev_RUNI.2016.n41.52680
} 


\section{Introducción}

El artículo tiene como finalidad preguntarse sobre algunas de las dinámicas espaciales más importantes en la violencia derivada del conflicto armado colombiano, concretamente, entre los años 1998 y 2012. Ello, con atención a las dos guerrillas más importantes del país, las Fuerzas Armadas Revolucionarias de Colombia - FARC, y el Ejército de Liberación Nacional - ELN.

La pregunta de investigación fundamental trata de aclarar cuáles han sido las pautas de continuidad y cambio por parte del activismo y la presión guerrillera en Colombia en los años referidos, coincidiendo con la puesta en marcha de dos políticas de seguridad de clara confrontación, como son las de los presidentes Pastrana Arango (1998-2002) y Uribe Vélez (2002-2010). La hipótesis de partida es la de destacar un proceso paulatino de narcotización en ambas guerrillas, el cual ha terminado por transformar las propias lógicas del conflicto armado.

Narcotización, en tanto y en cuanto, la violencia se condensa en enclaves de carácter fronterizo, especialmente con Venezuela, Ecuador y Perú, o con salida a la vertiente del Pacífico. Es en estos enclaves donde los cultivos ilícitos se erigen como los principales escenarios en los que tiene lugar la presencia y el activismo guerrilleros. Este proceso, así, ha terminado por desnaturalizar profundamente a la guerrilla, a la vez que dificulta cualquier posibilidad de finalización militar al conflicto. De hecho, puede que por esto se puedan entender mejor los importantes avances que han tenido lugar en el marco de negociaciones que actualmente transcurren con las FARC en La Habana, Cuba.

Sobre la base de lo anterior, el presente trabajo de investigación consta de cuatro grandes partes. La primera, un apartado metodológico en el que se detalla la orientación de la investigación así como las técnicas de investigación utilizadas y la naturaleza de los datos procesados. La segunda, un marco teórico y un estado de la cuestión en la que se presentan los trabajos más relevantes y las líneas predominantes en la comprensión del conflicto armado colombiano, frente a las cuales se ubica este trabajo. También se identifican algunos de los conceptos clave que determinan el alcance temático de este trabajo. En tercer lugar se presentan los resultados, es decir, se interpretan, con base en lo anterior, las dinámicas espaciales de la violencia directa ejercida por las guerrillas colombianas entre 1998 y 2012, coincidentes, como se señalaba, en un contexto de paulatino debilitamiento en cuanto a lo que han sido sus tradicionales fuentes de financiación como son el secuestro y la extorsión. Finalmente, se abordan conclusiones que invitan a pensar en nuevos paradigmas de seguridad y en las nuevas posibilidades que desde la Geografía Política y la Investigación para la Paz se puede interpretar el alcance y sentido de un conflicto como el colombiano que, actualmente, se encuentra bajo nuevas posibilidades expeditivas tanto para la comprensión de la continuidad del conflicto, como para la comprensión de promover nuevas posibilidades en la construcción de paz.

\section{Metodología de la investigación}

La hipótesis nuclear que se presenta es la de entender que, entre 1998 y 2012, el comportamiento de las guerrillas en la geografía de la violencia derivada del conflicto colombiano ha atendido a una pauta de narcotización. Sobre la base de mayor activismo guerrillero en escenarios fronterizos, encontramos como pauta común una fuerte concurrencia de cultivos ilícitos. Es decir, tomando como variable dependiente el activismo guerrillero, operacionalizado en acciones armadas por municipio según la base de datos que a continuación se detalla, y como variable independiente, la existencia de cultivos ilícitos, operacionalizada en hectáreas cultivadas, igualmente, por municipio, el resultado es el siguiente: a mayor presencia de cultivos ilícitos, mayor activismo y presencia guerrillera. 
Esto, tanto en las FARC como en el ELN. Dicho de otro modo, cabría pensar en que los cultivos ilícitos son un factor clave a la hora de observar la evolución espacial de la violencia guerrillera en los últimos años

La base fundamental que sustenta este trabajo de investigación reposa en el valor agregado de toda una documentación, apenas trabajada de una manera parcial en algunas aportaciones académicas, pero ni mucho menos en la complejidad e integralidad que aquí se presenta. Todos los datos que se ofrecen fueron facilitados $-\mathrm{y}$ de ahí el agradecimiento por ello- por el Observatorio de Derechos Humanos y Derecho Internacional Humanitario de la Vicepresidencia de la República de Colombia - ODHDIH, por los cuales se tiene acceso a todo un desglose por año y municipio de indicadores relacionadas con la violencia guerrillera y a los que se añade una cartografía explicativa, igualmente, hasta el momento no interpretada. Particularmente, estas informaciones del ODHDIH provienen de los boletines diarios del Departamento Administrativo de Seguridad, para todo lo que concierne al período 1998-2010, y de la Policía Nacional y el Estado Mayor de las Fuerzas Militares, para los años 2011 у 2012.

A estos datos y cartografías hay que añadir el acceso a las bases de datos, tampoco de acceso abierto, que maneja la Oficina de Naciones Unidas contra el Delito y el Crimen Organizado, UNODC, y que es de gran importancia a efectos de poder operacionalizar la hipótesis de la narcotización del activismo guerrillero en hectáreas y por municipio.

Junto a lo anterior, concurre una observación directa en casi doscientos municipios en contexto de violencia guerrillera, la mayoría, a su vez, con problemas de cultivo ilícito. Asimismo, se suman diferentes entrevistas en profundidad que enriquece parte de las consideraciones planteadas, respondiendo al propósito de incorporar el testimonio de actores directamente involucrados o conocedores de la dimensión real que aúna violencia guerrillera con narcotráfico. Esto, porque, casi siempre, es un tema que, en líneas generales, tiende a ser negado por las comunicaciones oficiales de los grupos guerrilleros. Sin embargo, sensu contrario, todos los testimonios que se integran coinciden en reconocer el factor clave que los cultivos ilícitos representan en la financiación y en los intereses económicos de los grupos guerrilleros.

Es así que se puede destacar la presencia, del lado de las Autodefensas Unidas de Colombia $^{2}$, del testimonio de uno de los comandantes de mayor importancia en la estructura del paramilitarismo colombiano durante los años objeto de estudio. Se trataría de Edward Cobos Téllez, "Diego Vecino", preso en el establecimiento carcelario de Bogotá, "La Picota", jefe político de las AUC y máximo comandante de Bloque Héroes de Montes de María.

Por el lado de las FARC estarían presentes los testimonios de Daniel Sierra Martínez, "Samir", quien tras más de dos décadas en las FARC llegó a ser el segundo comandante de las FARC en el poderoso Frente 5, operativo en Urabá, donde trató de obtener arraigo en esta zona bananera, compitiendo por el control de las masas con el Ejército Popular de Liberación - EPL. También se agrega el testimonio de Elda Neyis Mosquera, "Karina", excomandante del Frente 42 de las FARC, operativo en Caldas, y que junto con el anterior, colabora para el gobierno como agente de paz en el departamento de Antioquia.

\footnotetext{
${ }^{2}$ La organización que de manera más importante, articula el fenómeno paramilitar en Colombia, entre 1997 y 2005 .
} 
De parte del ELN, se recoge el testimonio de Carlos Arturo Velandia, "Felipe Torres", actualmente en libertad, pero que durante treinta años en la estructura guerrillera, fue uno de los miembros de la Dirección Nacional, esto es, parte del Comando Central - COCE, del ELN. Junto a él se incluye un fragmento de la entrevista con José Luis Ramírez Herrera, alias "Byron", antiguo jefe militar del ELN en el frente Carlos Alirio Buitrago (CAB), uno de los más importantes de esta guerrilla, y recluido actualmente en el establecimiento carcelario de Itagüí, una vez que fue capturado, en 2005.

Finalmente, del lado del Estado colombiano se incorporan dos testimonios. El primero, un General en retiro de la Policía Nacional, pero que durante buena parte de su vida profesional fue reconocido por sus acciones contra la inteligencia guerrillera. Buen conocedor y directo decisor sobre algunas de las lógicas de las políticas de seguridad acontecidas en Colombia pero que por razones de seguridad resulta obviada su identidad. El segundo, sería un personero ${ }^{3}$ de la región del Catatumbo en Norte de Santander, la segunda región con más cultivos de coca de todo el país, y que cuenta con ingentes niveles de presencia guerrillera aunque, como en el caso anterior, se preserva su identidad.

\section{Marco teórico y estado de la cuestión}

El conflicto colombiano ha sido objeto de estudio desde muy diferentes aristas y perspectivas, siendo predominantes algunos temas que son los que, mayormente, han concentrado el objeto de estudio que se plantea. Así, destacan los estudios sobre La Violencia ${ }^{4}$, el análisis de las causas económicas del conflicto ${ }^{5}$, la historia de los grupos armados ${ }^{6}$, el impacto económico del conflicto ${ }^{7}$, la dimensión militar del mismo $^{8}$, o su proyección a nivel regional o internacional ${ }^{9}$.

\footnotetext{
${ }^{3}$ Es la institución que, integrada en la Defensoría del Pueblo, se encarga de preservar la garantía de los Derechos Humanos en el municipio.

${ }^{4}$ Contexto de guerra civil partidista en Colombia, entre 1948 y 1965, que deja consigo más de 200.000 víctimas mortales. Destacan los trabajos de Guzmán, Gonzalo; Fals Borda, Orlando y Umaña, Eduardo (1962): La Violencia en Colombia, Bogotá, Tercer Mundo Editores; Oquist, Paul (1978): Violencia, conflicto y política en Colombia, Bogotá, Instituto de Estudios Colombianos; Sánchez, Gonzalo y Meertens, Donny (1983): Bandoleros, gamonales y campesinos, Bogotá, El Áncora Editores; y Henderson, James D. (1984): Cuando Colombia se desangró. Un estudio de la Violencia en metrópoli y provincia, Bogotá, El Áncora Editores.

${ }^{5}$ Un trabajo de referencia a tal efecto es el de Sánchez, Gonzalo (2009): Colombia: violencia y democracia. Comisión de Estudios para la Violencia, Bogotá, Editorial La Carreta.

${ }^{6}$ Sobre las historia del paramilitarismo se pueden destacar a Medina, Carlos (1990): Autodefensas, paramilitares y narcotráfico en Colombia. Origen, desarrollo y consolidación. El caso "Puerto Boyacá”, Bogotá, Editorial de Documentos Periodísticos; y Duncan, Gustavo (2006): Los señores de la guerra, Bogotá, Editorial Planeta. Sobre el ELN es muy recomendable el trabajo de Medina, Carlos (1996): ELN: una historia contada a dos voces, Bogotá, Rodríguez Quito Editores. Finalmente, sobre las FARC cabría destacar a Pécaut, Daniel (2008): Las FARC, ¿una guerrilla sin fin o sin fines?, Bogotá, Editorial Norma; y a Pizarro, Eduardo (2011): Las FARC (1949-2011). De guerrilla campesina a máquina de guerra, Bogotá, Editorial Norma.

${ }^{7}$ Los primeros trabajos, a tal efecto, serían los de Deas, Malcom y Gaitán, Fernando (1995): Dos ensayos especulativos sobre la violencia en Colombia, Bogotá, Tercer Mundo Editores; y Trujillo, Edgar y Badel, Martha: "Los costos económicos de la criminalidad y la violencia en Colombia: 1991-1996", Archivos de Macroeconomía, no. 76, (2008), pp. 1-49.

${ }^{8}$ Deben destacarse los trabajos de Leal, Francisco (1994): El oficio de la guerra. La seguridad nacional en Colombia, Bogotá, Tercer Mundo Editores; y Leal, Francisco (2006): En la encrucijada, Colombia en el Siglo XXI, Bogotá, Editorial Norma. También, Vargas, Alejo: "El conflicto interno armado colombiano y sus efectos en la seguridad en la región Andina", Ciencia Política, nº. 2, (2006), pp. 168-202.

${ }^{9}$ Cabe mencionar, desde una óptica de Relaciones Internacionales, y entre muchos otros a Rangel, Alfredo (1998): Colombia, guerra en el fin de siglo, Bogotá, Tercer Mundo Editores; Tickner, Arlene: "Colombia es lo que los actores estatales hacen de ella. Una (re)lectura de la política exterior colombiana hacia Estados Unidos", en Ardila, Martha; Cardona, Diego y Arlene Tickner (eds.) (2002): Prioridades y desafios de la política exterior colombiana, Bogotá, FESCOL, pp. 353-393; Tickner, Arlene: “Intervención por invitación. Claves de la política
} 
No obstante, el análisis espacial de la violencia, o ha quedado reducido a la noción recurrida, a inicios de la década pasada, de Estado fallido ${ }^{10}$ o focalizada en aspectos concretos como la relación entre despojo de tierras, ruralización y violencia ${ }^{11}$; las necesidades socioeconómicas que lastran el fortalecimiento institucional del Estado ${ }^{12}$ o el control de recursos y corredores estratégicos que afectan al conflicto armado. ${ }^{13}$ Sin embargo, además de que la Geografía Política, no es un enfoque recurrido ni protagónico en la comprensión de las lógicas que acompañan al conflicto armado, cuando se han incorporado análisis espaciales, estos se han centrado en planteamientos locales específicos ${ }^{14}$ o bien a efectos de analizar dimensiones más específicas como la violencia urbana. ${ }^{15}$

Si de por sí la Geografía Política no es una disciplina de estudio recurrida para entender la violencia guerrillera en Colombia, tampoco lo es el análisis espacial de los cultivos ilícitos, más allá de los informes de UNODC. Es decir, la única literatura existente es la producida por estos informes anuales de Naciones Unidas, pero no existe, por ejemplo, un análisis que trate de integrar la evolución de los cultivos ilícitos con el activismo guerrillero, de una manera pormenorizada, inspirada en series temporales, tal y como propone este trabajo. Asimismo, tampoco existen trabajos que traten de integrar las ópticas estrictamente estatales con las dinámicas sub-estatales, igualmente acontecidas.

De hecho, el tema de los cultivos ilícitos en Colombia, generalmente, se ha abordado desde otras perspectivas, como la afectación al mercado de las drogas ${ }^{16}$, la relación con las

exterior colombiana y de sus debilidades principales", Colombia Internacional, n ${ }^{\circ} 65$ (junio 2007), pp. 90-111; y Otero, Diego (2010): El papel de los Estados Unidos en el conflicto armado colombiano, Bogotá, Ediciones Aurora.

${ }^{10}$ Patiño, Carlos (2003): El mito de la nación violenta, Medellín, Universidad Pontificia Bolivariana; Sandoval, Ignacio (2004): Callejón con salida... hacia una nueva política nacional de paz, Bogotá, PNUD; y Urrego, Miguel A.: "La crisis del Estado nacional en Colombia. La perspectiva del Estado y sus funciones", Diálogos de Saberes: investigaciones y ciencias sociales, $\mathrm{n}^{\circ} 22$ (2005), pp. 156-168.

${ }^{11}$ Reyes, Alejandro (1993): Geografia de la violencia en Colombia. Informe de investigación, Bogotá, IEPRI; y Reyes, Alejandro (2009): Guerreros y campesinos. El despojo de la tierra en Colombia, Bogotá, Editorial Norma.

${ }^{12}$ Mesclier, Évelyne (1999): Dinámicas socioeconómicas en el espacio colombiano, Bogotá, DANE.

${ }^{13}$ Echandía, Camilo (1999): Geografía del conflicto armado y las manifestaciones de la violencia en Colombia, Bogotá, Universidad de Los Andes - CEDE y Echandía, Camilo (2006): Dos décadas de escalamiento del conflicto armado en Colombia 1986-2006, Bogotá, Universidad Externado. Asimismo, Salas, Luis G.: "Corredores y territorios del conflicto armado colombiano: una prioridad en la geopolítica de los actores armados", Perspectiva Geográfica, vol. 15 (2010), pp. 9-36; y Salas, Luis G.: "Lógicas territoriales y relaciones de poder en el espacio de los actores armados: un aporte desde la geografía política al estudio de la violencia y el conflicto armado en Colombia, 1990-2012", Cuadernos de Geografía, vol. 24, n 1, (2015), pp. 157-172.

${ }^{14}$ González, Fernán (ed.) (2012): Conflicto y territorio en el oriente colombiano, Bogotá, CINEP; y González, Fernán (ed.) (2014): Territorio y conflicto en la Costa Caribe, Bogotá, CINEP.

${ }^{15}$ Castillo, María del P.: "Las redes del conflicto: el caso del Valle del Cauca", Revista Sociedad y Economía, no 7 (2004), pp. 25-44; Giraldo, Jorge: "Conflicto armado urbano y violencia homicida", Revista Latinoamericana de Seguridad Ciudadana, no. 5 (septiembre 2008), pp. 99-113; y Vargas, Andrés R.: "Guerra civil y violencia de la Guerra contra las organizaciones sociales en Barrancabermeja: 1996-2003", Documentos CERAC, $\mathrm{n}^{\circ}$. 9, (diciembre 2008), 15 pp.

${ }^{16}$ Deben destacarse las aportaciones de Mejía, Daniel: "La guerra contra la producción y el tráfico de drogas: una evaluación económica del Plan Colombia", Debates de coyuntura económica, no 76 (mayo 2009), pp. 16-20 y Mejía, Daniel: "The War on Drugs under Plan Colombia”, Zedillo, Ernesto y Haynie Wheeler (eds.) (2012) Rethinking the "War on Drugs" Through the US-Mexico Prism, New Haven, Yale Center for the Study of Globalization, pp. 19-32. 
dinámicas de la globalización ${ }^{17}$ o de acuerdo a las concepciones que se proponen, sobre las "nuevas guerras". 18

Más recurrida ha sido la dimensión que aborda el conflicto colombiano desde la literatura en Investigación para la Paz y la Resolución de Conflictos. De hecho, el conflicto colombiano se ha tratado de explicar desde la saqueabilidad de los recursos ${ }^{19}$; desde la maldición de los recursos. ${ }^{20}$; o desde la violencia estructural que soporta que son los condicionantes económicos y sociales los que afectan o determinan los comportamientos violentos. $^{21}$

Sea como fuere, no se puede obviar que nos encontramos ante un conflicto como el colombiano, que se caracteriza por su alta intensidad, en la medida en que se siguen produciendo más de 1.000 muertes anuales directamente relacionadas con el mismo, y que afecta a cerca del $20 \%$ de municipios del país, siendo la causa primera de los más de cinco millones de desplazamientos forzados que se registran en la actualidad ${ }^{22}$. A su vez el conflicto colombiano se puede entender como un conflicto prolongado, en tanto y en cuanto sus orígenes directos se remontan a 1964, hundiendo sus raíces, incluso, en los años treinta ${ }^{23}$. También se puede entender como un conflicto de soberanía escindida, habida cuenta del amplio control territorial de las guerrillas que pondría en tela de juicio el concepto clásico de monopolio legítimo de la violencia. ${ }^{24}$

Existen incluso otras opciones desde las que catalogar al conflicto colombiano. Bien como guerra civil ${ }^{25}$; bien como un problema de terrorismo, desde un intento de relativizar e

\footnotetext{
${ }^{17}$ Véase Henderson, James D. (2010): Víctima de la globalización. La historia de cómo el narcotráfico destruyó a Colombia, Bogotá, Siglo del Hombre Editores.

${ }^{18}$ Véase Kaldor, Mary (1999): New and Old Wars: Organized Violence in Global Era, Cambridge, Polity Press; Kaldor, Mary: "In Defence of New Wars", Stability, vol. 2, no. 1 (marzo 2013), pp. 1-16; y Kalyvas, Stathis: “New and Old Civil Wars. A Valid Distinction?", World Politics, Vol. 54, no. 1 (octubre 2001), pp. 99-118.

19 Así lo proponen, por ejemplo, los trabajos de Keen, David: "War and Peace: What's the Difference?", International Peacekeeping, vol.7, no.4 (marzo 2000), pp. 1-22; Berdal, Mats y Malone, David (2000): Greed and Grievance: Economic Agendas in Civil Wars, Boulder, Lynne Rienner Publishers; y Nasi, Carlo y Rettberg, Angelika. (2005): "The Interlink Between Resources, Development and Conflict: Conflict Over Coffee and Bananas in Colombia", 46th Annual ISA Convention, Honolulu.

${ }^{20}$ En Collier, Paul; Hoeffler Anke y Soderbom, Mans: "On the duration of civil war", Journal of Peace Research, Vol. 41, nº 3 (mayo 2004), pp. 253-273.

${ }^{21}$ Galtung, Johan (1998): Tras la violencia, 3R: reconstrucción, reconciliación, resolución. Afrontando los efectos visibles e invisibles de la guerra y la violencia, Bilbao, Gernika Gogoratuz; Galtung, Johan (2003): Paz por medios pacíficos. Paz y conflicto, desarrollo y civilización, Bilbao, Gernika Gogoratuz; Kriesberg, Louis: "Conflict transformation", Peace and Conflict, vol. 2 (1999), pp. 413-425; o Miall, Hugh; Woodhouse, Tom; Mitchell, Chris y Ramsbotham, Oliver (2015): The Contemporary Conflict Resolution Reader, Cambridge, Polity Press.

${ }^{22}$ Según Wallensteen, Peter y Axell, Karin: “Armed conflict at the end of the Cold War", Journal of Peace Research, Vol. 30, no. 3 (agosto 1993), pp. 331-346.

${ }^{23}$ Gilhodès, Pierre (1972): Las luchas agrarias en Colombia, Bogotá, Editorial La Carreta; y Legrand, Catherine (1988): Colonización y protesta campesina en Colombia, Bogotá, Centro.

${ }^{24}$ Ortiz, William (2006): Los paraestados en Colombia. Tesis doctoral dirigida por Antonio Trinidad Requena. Universidad de Granada; y Kalyvas, Stathis: "Promises and pitfalls of an emerging research program: The microdynamics of civil war", en Kalyvas, Stathis; Shapiro, Ian y Masoud, Tarek (eds.) (2008): Order, Conflict and Violence, Cambridge, Cambridge University Press, pp. 397-421.

${ }^{25}$ Rangel, Alfredo: "Naturaleza y dinámica de la guerra en Colombia", en Cárdenas, Martha y Rodríguez, Manuel (eds.) (1993): Guerra, sociedad y medio ambiente, Bogotá, Universidad de Los Andes, pp. 49-66; y los trabajos de Lair, Eric: "Una guerra contra los civiles", Colombia Internacional, no 49 (diciembre 2000), pp. 135147; y Lair, Eric: “Transformaciones y fluidez de la guerra en Colombia: un enfoque militar”, Sánchez, Gonzalo y Lair, Eric (eds.) (2004): Violencias y estrategias colectivas en la región andina, Bogotá, Grupo Editorial Norma, pp. 103-143.
} 
infravalorar la dimensión real del mismo. ${ }^{26}$ Quizá en estos términos cabría más bien aceptar la noción, por ejemplo, de "guerra ambigua",27, al poderse entender que en Colombia, lo que ha dominado ha sido una lógica de intereses compartidos en la que mientras que las fuentes de poder económico, como el secuestro, la extorsión o el control sobre los cultivos ilícitos quedasen satisfechos, se garantizaba un orden local sui generis ${ }^{28}$. Buena prueba de esto se sintetizaría en las palabras que, para este trabajo, proporcionaba la ex-comandante del Frente 42, Karina, cuando señalaba que:

"Las FARC desde los ochenta y toda la década de los noventa tuvieron un gran arraigo en la región del Urabá, inicialmente con el Frente 5. Pero allí no había Estado. Allí había mucho abandono y pobreza y el orden local era de las FARC. Mucha gente nacía, crecía y moría en las FARC. Jamás tuvimos que conseguir una res o cultivar el campo. Eso nos lo daba la población, hasta que en el año 2000 llegan las AUC y comienzan los desplazamientos y despojos de tierra. Solo a partir de entonces, las FARC tienen que hacer algo que nunca antes hicieron, al proveérselo la población civil: las FARC tienen que sembrar. Nos tocó sembrar, tanto en el Urabá como en el oriente antioqueño. (Sin embargo) jamás, jamás nos sacaron de allí donde las FARC éramos verdaderamente poderosas. Teníamos todo el control. De hecho, hay sitios del país donde las FARC siguen siendo muy muy poderosas". (Entrevista personal, mayo de 2015).

Lo que resultaría más claro es entender que el conflicto colombiano se erige desde una dimensión bidimensional (positiva-negativa, crisis-oportunidad) respecto de la que convergen objetivos incompatibles cuya superación requiere de cómo se entiende la noción de paz. El propio Galtung concibe el conflicto como una interacción entre crisis y oportunidad ${ }^{29}$ que, en el caso de Colombia, debe entenderse de acuerdo a un Estado sin control territorial, institucionalmente debilitado, y con una lógica de disputa de recursos, que van desde el despojo de tierras y el secuestro hasta el narcotráfico, y que alimentan las dosis de la violencia armada de parte de grupos irregulares. Precisamente, lo que aquí se trata es de reivindicar la importancia de esta interpretación sobre cómo ha evolucionado el activismo guerrillero en los últimos años.

Al respecto, la oportunidad que plantea este déficit del Estado colombiano concurre con una confrontación de intereses en la medida en que éste, especialmente desde 1999, busca expandir sus redes de poder territorial y combatir la faceta armada y económica de la guerrilla. Todo, en torno a una dimensión horizontal, de disputa por lógicas de poder sobre los recursos y también con base en el control territorial. Sin embargo, se añade una relación vertical que termina teniendo a la población civil como el gran damnificado, al interactuar localmente de acuerdo a lógicas de violencia particulares que bien suponen el desarraigo y el desplazamiento forzado, bien la inclusión en comunidades de legitimación que terminan por desplazar y relegar al Estado a posiciones de debilidad.

A la vez, para Galtung todo conflicto responde a cuatro dimensiones de acuerdo a su escala geográfica de desarrollo: micro, meso, macro y mega ${ }^{30}$. A nivel micro, en este trabajo se podrían encontrar algunas cuestiones concretas, habida cuenta de la dimensión municipal planteada, añadiéndose la perspectiva tanto meso como macro, dada la identificación de regiones y el recurso continuo al Estado como escala geográfica de referencia. De otro lado, el

\footnotetext{
${ }^{26}$ Gaviria, José O. (2005): Los sofismas del terrorismo. Bogotá, Editorial Planeta.

${ }^{27}$ Rashid, Ahmed (2001): Los Talibán. El Islam, el petróleo y el Nuevo Gran Juego en Asia Central. Barcelona, Península; Collier, Paul (2000): Economic causes of civil conflict and their implications for policy, Washington, Banco Mundial; y Richani, Nazih: "The Political Economy of Violence: The War System in Colombia”, Journal of Interamerican Studies and World Affairs, Vol. 39, nº 2 (junio 1997), pp. 37-82.

${ }^{28}$ Acemoglu David y Robinson, James (2012): Por qué fracasan los países, Barcelona, Ediciones Deusto.

${ }^{29}$ Galtung, Paz por medios pacíficos..., op. cit., p. 8

${ }^{30}$ Galtung, Johan (2003): Trascender y transformar. Una introducción al trabajo de conflictos, México D.F., Transcend-Quimera.
} 
nivel supra-nacional, por cuestiones metodológicas y de limitación, termina siendo desatendido, si bien, es innegable su importancia en la afectación transfronteriza que el conflicto tiene no solo en Ecuador, Venezuela o Perú, sino también en Estados Unidos o en la comprensión trasnacional de la agenda negativa. Antes de finalizar esta aproximación teórica a la comprensión del conflicto armado colombiano, conviene abordar las tres dimensiones de la violencia que caracterizan a cualquier investigación como la propuesta. Ello, en tanto que, como señala Galtung, la violencia llevada a cabo en Colombia terminaría por ser la máxima expresión de la imposibilidad de poder transformar el conflicto armado por medios pacíficos $^{31}$. Una violencia que en el caso de Colombia, concurre sobre la base de las tres tipologías planteadas por la aportación teórica del académico noruego: violencia directa, violencia estructural y violencia cultural si bien, solo la primera de estas será la prioritaria a efectos del análisis propuesto. ${ }^{32}$

La violencia directa sería como la violencia manifiesta, en términos físicos, verbales o psicológicos pero que en el caso colombiano, a efectos de esta investigación, serían los actos violentos de las guerrillas, es decir, concibiendo como tales combates unilaterales, secuestros, extorsiones, ataques terroristas, desplazamiento forzado, muertes violentas o masacres.

Relacionada con lo anterior, pero atendida solo de manera tangencial estaría la violencia estructural, entendida como la violencia que hace parte en sí de los sistemas sociales, políticos, y económicos dentro de Colombia y que permite pensar en su concurrencia como caldo de cultivo explicativo de las dinámicas de la violencia directa. Es decir, la violencia estructural sería una violencia indirecta, sustentada por injusticia y desigualdad. Al respecto, cabría entender la violencia estructural como una violencia institucionalizada e interiorizada que, como recoge la Comisión Sudamericana de Paz, se desarrolla a través de la pobreza y la exclusión, y termina por desarrollar un escenario de inestabilidad económica, política y social que pone en peligro la seguridad de las personas, además de acoger dinámicas reiteradas de violencia. ${ }^{33}$ Dinámicas que, por ejemplo, afectarían a quienes se ven privados de seguridad o anulados en cuanto a disponer oportunidades de desarrollo personal. ${ }^{34}$

Finalmente, como tercera dimensión, estaría la violencia cultural, y que repercute sobre aquellos aspectos de la cultura dentro del ámbito simbólico de nuestra experiencia, es decir, la suma de mitos y traumas que justifican un marco de violencia directa. Es decir, las dos dimensiones descritas, violencia directa y violencia estructural, se acompañarían de un tercer nivel que sería el de la violencia cultural, al entender que la violencia se termina por consolidar como una forma de vida, de acuerdo a manifestaciones explícitas e implícitas de poder.

\section{Las finanzas de las guerrillas. Secuestro, extorsión y narcotráfico}

Como se señalaba anteriormente, la relación entre cultivos ilícitos y activismo guerrillero ha sido planteada a la hora de entender el conflicto colombiano, en base a presunciones muy generalistas y poco analizadas empíricamente. De hecho, una primera limitación es que,

\footnotetext{
${ }^{31}$ Galtung, Johan (1998): Tras la violencia, 3R: reconstrucción, reconciliación, resolución. Afrontando los efectos visibles e invisibles de la guerra y la violencia, Bilbao, Gernika Gogoratuz.

${ }^{32}$ Galtung, Johan (2003): Violencia Cultural, Bilbao, Gernika Gogoratuz.

33 Comisión Sudamericana de Paz, Seguridad y Democracia (1994): Propuestas emanadas de los Foros Regionales de Actores sociales para promover una Agenda social en América Latina. Santiago de Chile, CSPSD.

${ }^{34}$ Rifkin, Jeremy (1996): El fin del trabajo. Nuevas tecnologías contra puestos de trabajo: el nacimiento de una nueva era, Ginebra, ILO.
} 
generalmente, no se incorporan testimonios que reconozcan, con "conocimiento de causa", esta circunstancia. Así, un primer testimonio sería el de un General (r) de la Policía, quien entrevistado para esta investigación reconocía taxativamente la relación del activismo guerrillero con el narcotráfico:

\begin{abstract}
"No piense que el ELN no depende del narcotráfico. Lo hace igual que las FARC. El matiz, sin embargo, se encuentra en que el ELN siempre ha tratado de manejar las bases cocaleras de otro modo, mucho más respetuoso, e integrándolos en su estructura, al entender que son proyectos necesarios de inclusión y que conduce al hecho de que el ELN tenga más base y apoyo en términos de organización tanto social como política. Fíjese, nunca se ha hablado de extraditar un comandante del ELN, y en buena medida es por eso. Es muy diferente a unas FARC que son mucho más violentas y que, cuando se imponen al ELN predominan en su accionar aunque en muchas ocasiones el ELN trata de transar para apoyar a sus bases de legitimación" (Entrevista personal, abril de 2015).
\end{abstract}

Lo cierto es que respecto de las finanzas de las guerrillas, existen dos trayectorias claramente diferenciadas. Inicialmente, las FARC rechazaban cualquier relación con la marihuana o la coca, por entender que desvirtuaban a las comunidades receptoras y se contravenía a lo que debía ser el "espíritu guerrillero". No obstante, terminan por aceptar lo que se llama el "impuesto de gramaje", una vez que tiene lugar la VIII Conferencia Guerrillera de 1989. Ese gramaje se justificaba en sí como un cobro al cultivo de coca, con el propósito de proteger a los agricultores frente a la llegada de grupos paramilitares, evitando con ello, el despojo de tierras ${ }^{35}$. Sin embargo, las zonas de dominación territorial de las FARC añadían una segunda contrapartida a los propios narcotraficantes, la cual, según Pécaut, incorporaba la posibilidad de disponer de laboratorios, pistas clandestinas y rutas de evacuación de los cargamentos ${ }^{36}$. De hecho, el propio Pécaut, aunque tímidamente, es de los primeros, junto con los trabajos de Echandía en plantear una posible periferialización del activismo de las FARC con base en una proximidad al control del tráfico de drogas ${ }^{37}$.

Tal y como reconocen algunos como Aguilera, el gramaje, en sus inicios, ascendía a un 15\%, aproximadamente, de cada transacción realizada con pasta o base de coca, lo cual marca un punto de inflexión de lo que será conocido como la diferencia entre frentes ricos y frentes pobres de las $\mathrm{FARC}^{38}$. Empero, es cierto que los inicios de la relación de las FARC con el narcotráfico, en la segunda mitad de los ochenta, ni mucho menos fueron sencillos. Especialmente, porque los frentes ricos hacían evidencia de su opulencia a modo de joyas o coches de lujo que, como reconoció un Informe de las FARC de 1987, desnaturalizaba la idea de guerrillero pobre, obrero y trabajador del campo ${ }^{39}$. De hecho, el concepto de narcoguerrilla o narcoterrorismo aparece por primera vez en el trabajo de Palacio y Rojas, a inicios de los noventa. $^{40}$

\footnotetext{
${ }^{35}$ Maddaloni, Jon-Paul N.: "An Analysis of the FARC in Colombia: Breaking the Frame of FM 3-24", Comand and General Staff College, (mayo 2009), en http://www.cgsc.edu/sams/media/Monographs/MaddaloniJ21MAY09.pdf

${ }^{36}$ Pécaut, Daniel: "Las FARC: fuentes de su longevidad y de la conservación de su cohesión", Análisis Politico, $\mathrm{n}^{\mathrm{o}} 63$ (agosto 2008), pp. 22-50.

${ }^{37}$ Pécaut, Las FARC, ¿una guerrilla sin fin..., op. cit., p. 39; y Echandía Camilo; Bechara, Eduardo y Nossa, Irene: "Colombia: Estado del conflicto armado al final de la Administración de Álvaro Uribe", en Mathieu, Hans y Niño, Catalina (eds.) (2010): Seguridad regional en América Latina. Anuario 2010, Bogotá, Friedrich Ebert Stiftung en Colombia, pp. 136-172.

${ }^{38}$ Aguilera, Mario (2010): Las FARC: la guerrilla campesina 1949-2010, Bogotá, Arfo Editores.

${ }^{39}$ FARC-EP (1987): Informe Central al Pleno del Estado Mayor de las FARC-EP, 17-20 de febrero 1987.

${ }^{40}$ Palacio, Germán y Rojas, Fernando: "Empresarios de la cocaína, parainstitucionalidad y flexibilidad del régimen político colombiano: narcotráfico y contrainsurgencia", en Palacio, Germán (ed.) (1990): La irrupción del paraestado. Ensayos sobre la crisis colombiana, Bogotá, ILSA-CEREC, pp. 69-104.
} 
La proximidad de las FARC con la droga presenta una mayor cercanía ya en los años noventa, cuando se busca incrementar el pie de fuerza y disputar el control territorial al Estado. Hechos como la detención del gran capo de la droga brasileña, Fernandinho, en un territorio controlado por las FARC así como la caída de figuras clave en las finanzas de la guerrilla como el "Negro Acacio", al frente de los negocios del Bloque Oriental - casualmente el más poderoso de las FARC y que se erige sobre vastos escenarios cocaleros-, invitan a pensar en una creciente participación. Así lo reconocía "Samir", segundo comandante del Frente 5, cuando era preguntado por ello:

"La fortaleza de las FARC gracias al narcotráfico es fundamental. Hacia el interior de las FARC nos llegó una circular firmada por Manuel Marulanda en 2006 en la que se ordenaba a todos los bloques de las FARC recaudar 230 millones de dólares. Se busca expandirnos en plena Política de Seguridad Democrática. Ello, porque Manuel Marulanda pensaba que para 2010 sería posible la primera gran ofensiva nacional. Todo sin perder de vista armas y política y sin duda, el narcotráfico era la fuente de ingresos más importante para nosotros. De hecho, las AUC son conscientes de ese poder y es cuando nos disputan lo que vamos a llamar "la disputa del poder local". Una lucha en la cual, el que gana va a mantener la siembra y el procesamiento de coca"”. (Entrevista personal, agosto de 2015).

Similar testimonio sería el del exjefe paramilitar, "Diego Vecino", quien justificaba la expansión paramilitar sobre enclaves cocaleros como consecuencia del vasto poder que suponía este rubro para las FARC. Poder que, claramente, desequilibraba desfavorablemente la correlación de fuerzas con las guerrillas:

\footnotetext{
"Entre 1997 y 2001 nuestra financiación era totalmente sobre economía lícita, especialmente, agricultura y ganadería. Y también teníamos una cuota extorsiva. Pero desde 2001 se nos entrega el cobro de finanzas a los narcotraficantes, lo cual hasta ese momento lo hacía Vicente Castaño. Cobrábamos a los narcotraficantes que pasaban por la zona con búsqueda al golfo del Morrosquillo. Entre 2001 y 2004, cuando asumimos este rubro, esto nos suponía entre el 60 y el $65 \%$ mientras que el resto era legal. Es después de esto que las AUC, en el proceso de expansión que asume Castaño, buscan arrebatar los enclaves cocaleros de las FARC más importantes. Ahí estaba el poder y estaban las finanzas para la guerra". (Entrevista personal, mayo de 2015).
}

A tal efecto, resulta fácil entender el paso de las FARC del gramaje al procesamiento. Así lo señalan autoridades en el conocimiento del conflicto armado colombiano como el referido Pécaut, cuando señala cómo, poco a poco, las FARC han ido construyendo laboratorios propios que permiten ingresar cifras muy superiores a las provenientes del gramaje, sumando incluso el control de peaje a narcotraficantes y negociando directamente con ellos el precio de compra del producto. ${ }^{41}$

Sea como fuere, el valor real de narcotráfico en las finanzas de las FARC solo se comprende bajo estimaciones tentativas. Por ejemplo, para Henderson, hacia finales de los años noventa, el secuestro representaba, aproximadamente la tercera parte de los ingresos de las FARC, superados por un $54 \%$ de los beneficios obtenidos por el narcotráfico. ${ }^{42}$ Una aproximación más sólida sería la de Bejarano y Pizarro, quienes estiman que de las fuentes de financiación de las FARC, el $48 \%$ provendría del tráfico de drogas, el $36 \%$ fruto de la extorsión, el $8 \%$ derivado del secuestro, un $6 \%$ producto del robo de ganado más un $2 \%$ restante de actividades varias. ${ }^{43}$ En términos similares, las únicas estimaciones del gobierno, entienden que el narcotráfico representaba un $46.44 \%$ del total de los recursos de los cuales, el

\footnotetext{
${ }^{41}$ Pécaut, "Las FARC: fuentes de su longevidad...", op. cit., p. 39.

${ }^{42}$ Henderson, Víctima de la globalización ..., op. cit., p. 224.

${ }^{43}$ Bejarano, Ana M. y Pizarro, Eduardo (2001): "The Coming Anarchy: The Partial Collapse of the State and the Emergence of Aspiring State Makers in Colombia", Workshop at the Punk Center of Internacional Relations, Universidad de Toronto.
} 
45.9\% derivaba de las actividades de comercialización de clorhidrato de coca, frente a un $0.53 \%$ obtenido, presumiblemente, del impuesto de gramaje. El resto de rubros serían un $41.31 \%$ de la extorsión, un $6.75 \%$ del secuestro, un $1.39 \%$ el hurto de ganado, y un $7 \%$ restante de actividades criminales varias como asalto a entidades bancarias o hurto de combustibles. $^{44}$

Lo cierto es que con base en lo anterior, son muchos los que se aventurarían a considerar que el narcotráfico, sobre todo durante la primera mitad de la década anterior, terminó por suponer unos ingresos anuales superiores a los 500 millones de dólares. ${ }^{45}$

A diferencia de lo señalado, el ELN se ha caracterizado, tradicionalmente, por una estructura en sus ingresos bien diferente, fruto de una posición más renuente en cuanto a participar de la industria del narcotráfico. Así lo reconoce "Felipe Torres":

"Lo cierto es que la esencia del ELN siempre ha sido de subsistencia, es decir, con un proyecto pobre económicamente, en términos sociales, políticos y también ideológicos. El ELN jamás pretendió ser una organización como las FARC y, sin embargo, ello es clave para entender el hecho de que las guerras entrañan grandes costos. Yo te lo puedo reconocer porque fui jefe militar y sé lo que supone un contexto en el que no se produce y todo se consume. Además hay un factor adicional y es que, para ello, las FARC se involucraron en el negocio del narcotráfico y sobre los tres eslabones de la producción. Por su parte, el ELN nunca lo hizo por una decisión y convicción política. (Entrevista personal, mayo de 2015).

Así, Bejarano y Pizarro identifican una estructura en cuanto a sus ingresos bien diferente entre una guerrilla y otra. Sobre el 100\% de las fuentes de ingreso del ELN, un $60 \%$ provendría de la extorsión, un $28 \%$ del secuestro, un $6 \%$ del tráfico de drogas, un $4 \%$ del robo de ganado y, por último, un $2 \%$ de otro tipo de actividades criminales. ${ }^{46}$ De hecho, algunos análisis $^{47}$, plantean que la participación hasta 2007 de esta guerrilla en la industria del narcotráfico resultó tan ambigua como imprecisa y apenas, en una cuantificación general, llegaba a un millón de dólares. No obstante, en los últimos años se empieza a señalar una mayor presencia de esta guerrilla en escenarios relacionados con el narcotráfico. ${ }^{48}$ Incluso, trabajos anteriores, de finales de los noventa, apuntan la posibilidad de identificar escenarios

\footnotetext{
${ }^{44}$ Estimación de los ingresos y egresos de las FARC durante 2003, JIC, en http://static.iris.net.co/semana/upload/documents/Doc-1760 2008926.pdf

${ }^{45}$ Además de algunos de los trabajos mencionados, se pueden destacar los de Gutiérrez, Francisco: "Criminal Rebels? A Discussion on Civil War and Criminality from the Colombian Experience", Politics and Society, vol. 32, no 2 (junio 2004), pp. 257-285; Mackenzie, Eduardo, "FARC y Bacrim: un frente común”, Grupo de Estudios Estratégicos, Análisis 7814 (mayo 2010) http://www.gees.org/files/article/22052010151814_Analisis07814.pdf; Pataquiva, Germán N.: "Las FARC, su origen y evolución”, UNISCI Discussion Papers, nº 19 (enero 2009) pp. 154-185; Ríos, Jerónimo: "Las fuentes de poder social del paraestado en Colombia", en Requena, Miguel (ed.) (2010): Luces y sombras de la seguridad internacional en los albores del siglo XXI, Madrid, Instituto Universitario Gutiérrez Mellado, pp. 15-40; International Crisis Group: "Mejorar la política de seguridad en Colombia", Informe sobre América Latina, n. 23, (junio 2010), en

http://www.crisisgroup.org/en/regions/latin-america-caribbean/andes/colombia/B23-improving-security-policyin-colombia.aspx?alt lang=es o Constantino, Santiago D. y Lasa María A.: "Las industrias de las FARC: secuestro y narcotráfico", en Specchia, Nelson (ed.) (2010): Conflicto, guerrillas y búsqueda de la paz en Colombia. Córdoba, OVASI, pp. 79-90.

${ }^{46}$ Bejarano y Pizarro, "The Coming Anarchy..., op. cit., p. 5.

${ }^{47}$ Véase Bonilla, Laura: "ELN y el narcotráfico: una relación peligrosa”, El Espectador, 7 de julio de 2014.

${ }^{48}$ Véase International Crisis Group: “¿Se está avanzando con el ELN?”, Boletín informativo sobre América Latina, $\mathrm{n}^{\circ} 16$ (octubre 2007), en http://www.crisisgroup.org/en/regions/latin-americacaribbean/andes/colombia/b016-colombia-moving-forward-with-the-eln.aspx?alt lang=es
} 
próximos al cultivo ilícito en el sur de Bolívar y en la región del Catatumbo. ${ }^{49}$ Sin embargo, en los últimos años parece ser que esta relación más próxima se encuentra, particularmente, en Cauca, Nariño, Chocó, y en ocasiones en Antioquia y Arauca. Esto lo reconoce con desánimo el mismo "Felipe Torres":

\begin{abstract}
"Sin embargo, me apena reconocer que el ELN ha empezado a incursionar de unos años para acá en la fase que se relaciona con el gramaje sobre la coca. Incluso algunas estructuras han ido incluso más allá y han pactado con narcotraficantes y con proyectos de las Bacrim. Es fácil. Yo te cuido laboratorios y pistas de aterrizaje y, por ejemplo, a cambio tú me provees de armas. Es un intercambio de servicios en el que todos ganan pues en muchos enclaves de narcotráfico hay un modus vivendi en el que no hay interés de guerra entre actores sino contra el Estado, que termina siendo el enemigo común, aunque es evidente que todo esto ha desdibujado la imagen del ELN. Sinceramente, me apena ver esta situación cuando a nosotros, a mí y al "Cura Pérez ${ }^{50,}$, nos costó mucho mantenernos al margen del gramaje. Sin embargo, el pragmatismo en medio de la guerra se ha transformado en algunas estructuras en una dependencia de coca para mantenerse". (Entrevista personal, mayo de 2015).
\end{abstract}

De este modo, y de acuerdo a estas consideraciones, es de esperar una progresiva cercanía de las guerrillas de las FARC y el ELN respecto de los principales enclaves productores de coca que, sin embargo, parece ser más intuitiva que evidenciada. No obstante, la hipótesis de la narcotización de las guerrillas se puede entender, más allá de los testimonios recogidos y de la revisión bibliográfica, por el impacto de las políticas de seguridad, especialmente, puestas en marcha entre 1998 -año de inflexión en el conflicto colombiano por el proceso de negociación del Caguán, y el año 2012.

Entre 2002 y 2010 se va a destinar más de un 4\% del PIB a aspectos concernientes a seguridad y defensa, a lo que hay que adicionar otros 7.000 millones de cooperación estadounidense en el marco del Plan Colombia. Un Plan Colombia que, unido a la Política de Seguridad, supone un desembolso de más de 12.000 millones de dólares orientados a modernizar y optimizar la estructura de la Fuerza Pública. Tanto, que en el transcurso de la década, Colombia pasa de 110.000 policías a 160.000 , del mismo modo que sus efectivos militares pasan de poco más de 200.000 efectivos hasta 270.000. Unos datos que, como reconoce el Ministerio de Defensa, representan un incremento del $40 \%$ en el pie de fuerza del Estado. $^{51}$

Lo anterior, por ejemplo, permite la consecución de los grandes golpes estratégicos que repercuten y debilitan a las dos guerrillas pero, sobre todo, a las FARC. Así sucede con las Operaciones "Fénix", de 2008, "Sodoma", de 2010 y "Odiseo", de 2011. Tres operaciones que suponen, respectivamente, la baja de tres de los líderes más importante de la historia de las FARC, como es el caso de "Raúl Reyes", "Mono Jojoy" y "Alfonso Cano". De igual forma, se captura a otros líderes relevantes como "Simón Trinidad", en 2004, y se da de baja a otros hombres clave del Estado Mayor Conjunto como "Negro Acacio" (2007), "Martín Caballero" (2008) o "Iván Ríos" (2008). ${ }^{52}$

\footnotetext{
${ }^{49}$ Véase Fonseca, Daniel; Gutiérrez, Omar y Rudqvist, Anders (2005): Cultivos de uso ilícito en sur de Bolívar, Bogotá, PNUD.

${ }^{50}$ Manuel "Cura" Pérez fue, tras la figura de Camilo Torres, la personalidad que mayor importancia va a conferir al ELN en la construcción discursiva derivada de la teología de la liberación. Fue Comandante en jefe entre 1983 y 1998.

${ }^{51}$ Ministerio de Defensa: "Logros de la Política de Consolidación de la Seguridad Democrática" (noviembre de 2010), en

https://www.mindefensa.gov.co/irj/go/km/docs/Mindefensa/Documentos/descargas/estudios\%20sectoriales/info estadistica/Logros\%20de\%20Politica\%20CSD\%20Nov\%202010.pdf

${ }^{52}$ Ríos, Jerónimo: "Del Caguán a La Habana. Los diálogos de paz con las FARC en Colombia: una cuestión de correlación de fuerzas", Revista de Estudios en Seguridad Internacional, Vol. 1, nº1 (2015), pp. 63-83.
} 
Mapa 1: Presencia activa de la Fuerza Pública colombiana. Comparación entre 2002 y 2012
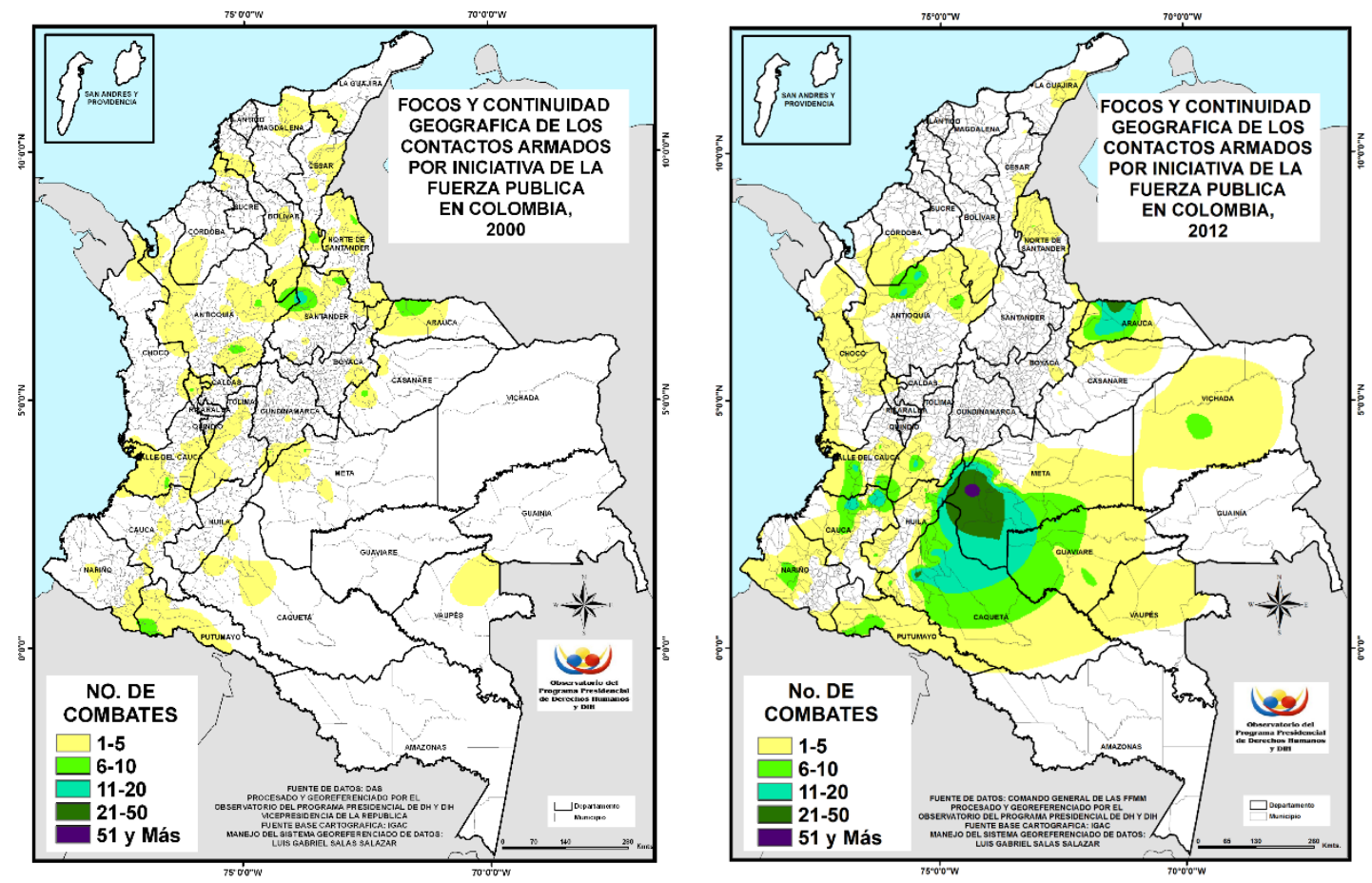

Fuente: ODHDIH

También se reduce la capacidad de acción, especialmente puesta de manifiesto en las cifras que acompañan al secuestro en Colombia y que recogen los anuarios sobre violencia de la Revista Criminalidad, editada por la Policía Nacional. Fruto del incremento en la presión de la Fuerza Pública y, habida cuenta de un debilitamiento de las estructuras guerrilleras, en el caso de las FARC, si entre 1998 y 2002 mantenían unos niveles próximos a los 800-900 casos al año, desde 2003 se comienza a apreciar un retroceso significativo, al pasarse de los 943 casos de secuestro de 2002, a los 654 de 2003, para seguir decayendo a los 299 de 2004. La tendencia va a seguir acentuándose, y entre 2006 y 2008 apenas se supera la perpetración de una centena de casos anuales, siguiendo a la baja hasta el punto de que en todo el año 2012, apenas se contabilizan 20 secuestros.

Lo mismo para el caso del ELN, que entre 1998 y 2002 superaba ampliamente los 700 casos de secuestros anuales para, incluso, aproximarse a los 900 casos en los años 2000 y 2001. No obstante, si en 2002 siguen siendo 777 los secuestros protagonizados por esta guerrilla, en el año siguiente la cifra decae hasta los 326, para continuar haciéndolo hasta los 138 casos en el año 2004. Así, los niveles de secuestro terminan por caer a mínimos históricos desde 2007 y hasta la actualidad, cuando en ningún caso se superan los 40 casos anuales siendo 33 los registros efectivamente contabilizados en el año 2012. 
Gráfico 1: Evolución de los secuestros cometidos por FARC y ELN entre 1998 y 2012

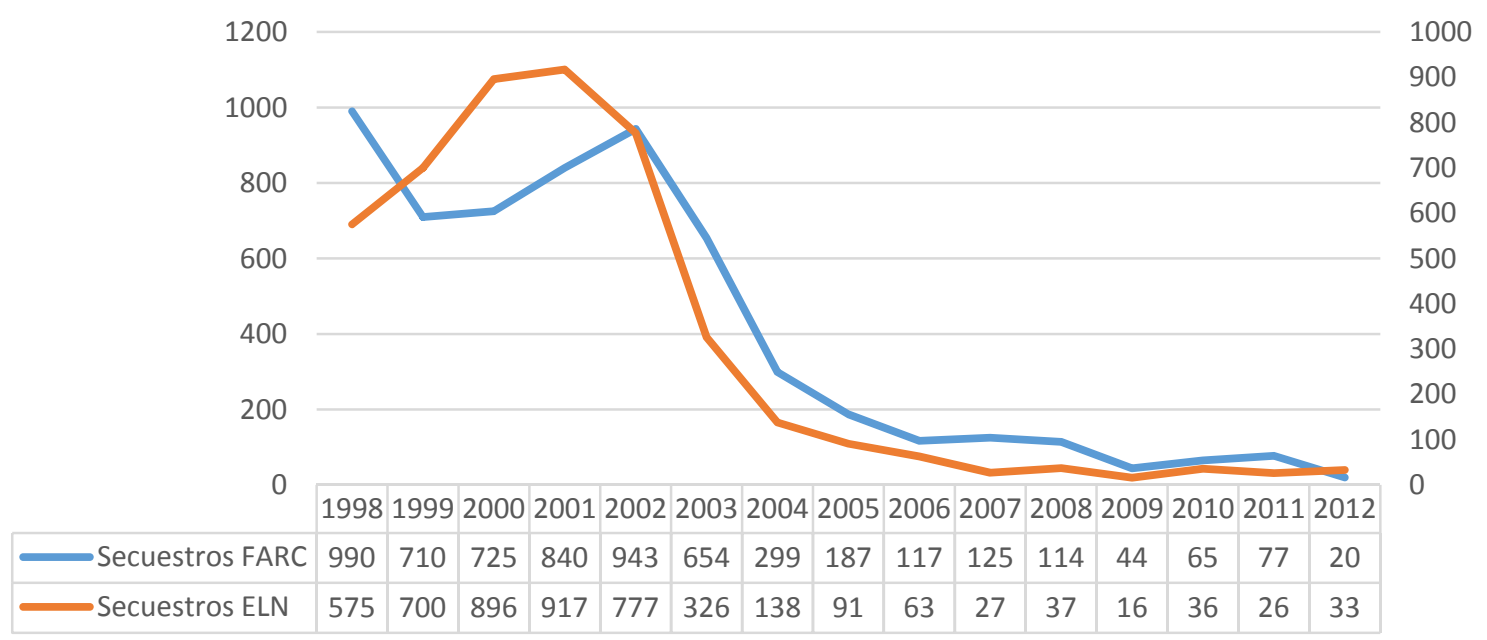

Fuente: Elaboración propia con base en los datos de Revista Criminalidad (2002- 2012)

Además, entre 2002 y 2010 se intensifica la lucha anti-narcóticos, llegándose a destruir 20.062 laboratorios cocaleros y a incautar 1.269 toneladas de cocaína. Tanto, que la superficie cultivada pasa de $130.364 \mathrm{Ha}$ para el año 2002 , a $58.073 \mathrm{Ha}$ para $2010^{53}$. Asimismo, decaen significativamente otras cifras propias del conflicto armado colombiano como las acciones de las FARC, que pasaron de 1.042 en 2002 a 724 en 2010, y en el caso del ELN, de más de 300 a apenas 65 . Tanto que, incluso, algunos estudios estimaron que solo entre 2002 y 2010, el ELN perdió hasta un $77 \%$ de su fuerza de combate, por un $83 \%$ para el caso de las FARC. $^{54}$

Dicho de otro modo, las FARC pasaron de casi 18.000 combatientes en 2002 a menos de 8.000 una década después, toda vez que el ELN redujo su número de efectivos, de 4.500 en 2002, a menos de 1.800 una década después. Todo, sin embargo, dentro de una lógica de enquistamiento, y hasta de relativa recomposición de la violencia, en la medida en que ésta se consolida en aquellos enclaves en los que el arraigo de los cultivos cocaleros persiste cuando no se intensifica, tal y como se podrá observar a continuación.

\section{Resultados: La narcotización del ELN entre 1998 y 2012}

Con base en lo descrito con anterioridad, hay indicios que invitan a pensar en un protagonismo creciente del ELN sobre enclaves con presencia de cultivos ilícitos, especialmente, habida cuenta de su debilitamiento armado y la reducción de su tradicional y primera fuente de ingresos: el secuestro.

Retomando el planteamiento hipotético del inicio, se trata de mostrar si es posible atender a un proceso de (re)localización del ELN sobre enclaves de cultivos de coca, esto es, observando si se puede apreciar una relación significativa entre sus dinámicas de activismo armado con la concurrencia de cultivos ilícitos allí donde tales se encuentran.

Hay que partir de la premisa de que el ELN ha sido una guerrilla cuyo repliegue territorial ha sido casi constante durante la década pasada. De hecho, si se observa la siguiente tabla, se

\footnotetext{
${ }^{53}$ UNODC: "Colombia. Monitoreo de cultivos de coca 2011" (junio de 2012), en https://www.unodc.org/documents/crop-monitoring/Colombia/Censo cultivos coca 2011.pdf

${ }^{54}$ Fundación Paz y Seguridad: "El debilitamiento de los grupos irregulares en Colombia, 2002-2008", Revista Coyuntura de Seguridad, nº. 23 (2008), pp. 5-11
} 
puede observar cómo su presencia municipal a lo largo del país se ha reducido entre dos terceras y tres cuartas partes, afectando a finales de 2012, a un total de 31 municipios sobre el total de 1.123 del país, y muy alejados, por ejemplo, de los 131 del año 2001. No obstante, a la vez, se aprecia una ligera recuperación tras 2008, cuando la presencia municipal de esta guerrilla llega al registro más bajo de los últimos treinta años.

Tabla 1: Evolución municipal y departamental de la presencia del ELN entre 1998 y 2012

\begin{tabular}{|l|l|l|l|l|l|l|l|l|l|l|l|l|l|l|l|}
\hline & 1998 & 1999 & 2000 & 2001 & 2002 & 2003 & 2004 & 2005 & 2006 & 2007 & 2008 & 2009 & 2010 & 2011 & 2012 \\
\hline $\begin{array}{l}\text { Municipios } \\
\text { con presencia } \\
\text { de ELN }\end{array}$ & 90 & 85 & 129 & 131 & 65 & 48 & 41 & 39 & 16 & 18 & 14 & 25 & 27 & 30 & 31 \\
\hline $\begin{array}{l}\text { Departamentos } \\
\text { con presencia } \\
\text { de ELN }\end{array}$ & 16 & 16 & 19 & 18 & 15 & 14 & 12 & 12 & 8 & 9 & 5 & 8 & 8 & 8 & 10 \\
\hline
\end{tabular}

Fuente: Elaboración propia con base en los datos del ODHDIH.

Se puede decir que el ELN se caracteriza porque, tradicionalmente, ha sido una guerrilla concentrada, fundamentalmente, en el nororiente del país, especialmente y como se puede observar en el siguiente mapa 1, en torno a los departamentos de Antioquia, sur de Bolívar Santander, Norte de Santander, Casanare y Arauca - en los que se entendía que se daban las condiciones socioeconómicas óptimas para emular un proceso revolucionario como el cubano. También en algunos departamento de la costa Atlántica, especialmente, La Guajira, Cesar, Magdalena y Sucre y, muy minoritariamente, en el suroccidente del corredor Pacífico, en los departamentos de Valle del Cauca, Cauca y Nariño - donde la interacción con el cultivo de coca era mayor.

Durante los años de la presidencia de Andrés Pastrana (1998-2002), con el ELN por fuera de las negociaciones de paz, la guerrilla se convierte en objetivo militar hasta el punto de que si en 1998 apenas se recogen 93 acciones militares unilaterales contra aquélla, en el año 2001, se contabilizan hasta 291 operativos. De hecho, hasta casi finales de 2007, los operativos militares de este tipo llegan a mantenerse, de forma constante, por encima de los 300 operativos anuales.

Mapa 2: Cartografía del activismo armado del ELN en el año 2000 y en 2012
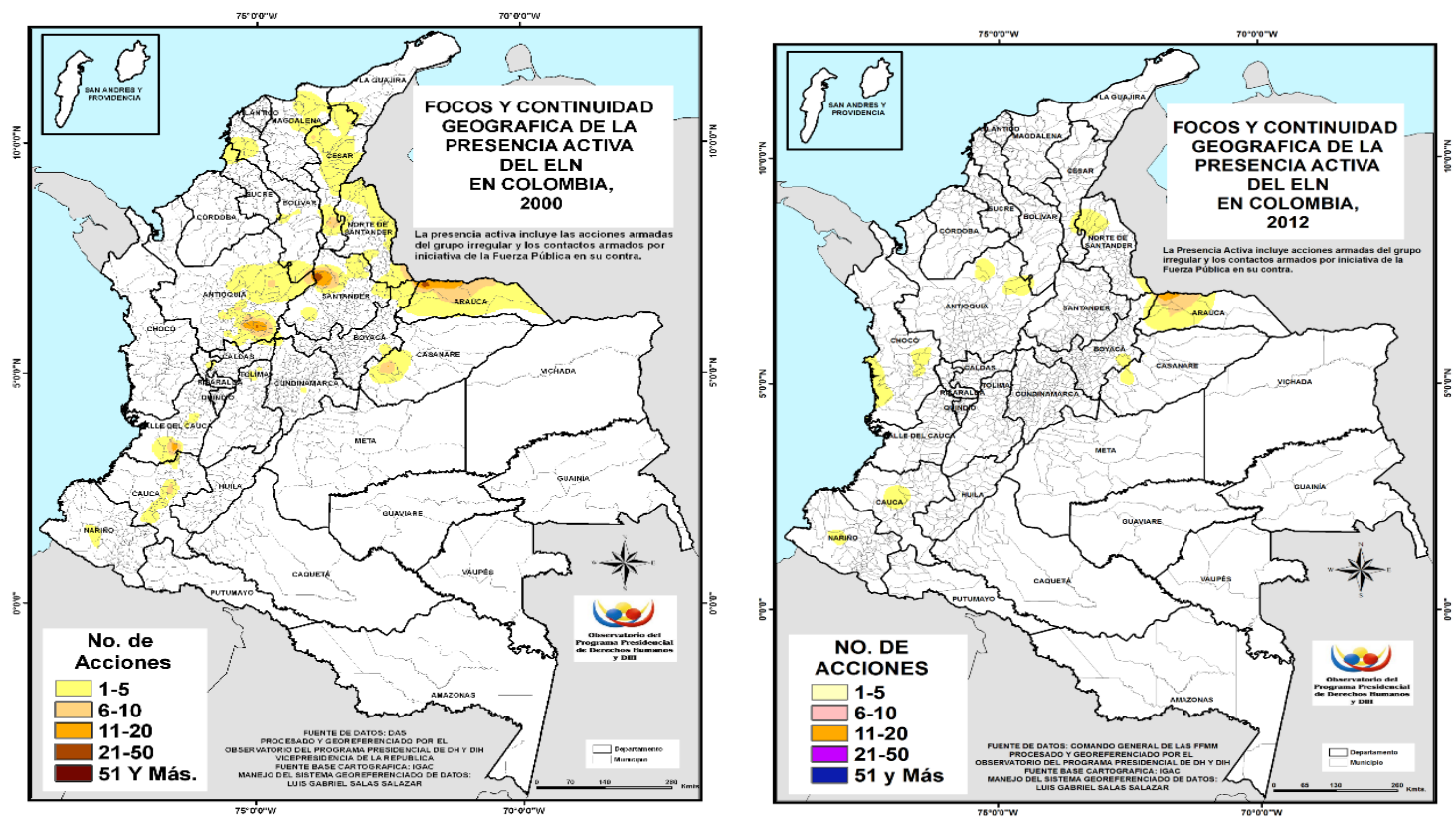

Fuente: ODHDIH 
A ello habría que añadir el particular daño que va a hacer el paramilitarismo, especialmente en el enclave estratégico de mayor valor, en torno a la región del Magdalena Medio y los enclaves de Antioquia, sur de Bolívar y Santander. En esta región, a inicios de la década pasada son especialmente combativos contra esta guerrilla tanto el Bloque Metro de las Autodefensas Unidas de Colombia, como el Bloque Central Bolívar. De ello da una excelente explicación el excomandante del poderoso Frente Carlos Alirio Buitrago, en Antioquia, "Byron":

"El CAB, como le decía, llegó a tener 300 hombres pero a diferencia de las FARC nosotros no somos ejército de un partido y, por tanto, nuestra organización era más flexible. Más parecida a Nicaragua. Así, la parte militar se configuraba según el objetivo. Era una guerra irregular de manera que yo dirigía operativos de 5 hasta 100 hombres, por ejemplo. Cuando llegan los paramilitares, entre 2001 y 2002, sobre todo tuvimos muchos combates con las AUC, pero también con las FARC. Nos dimos mucha bala. Eso nos generó muchas deserciones y la dificultad de justificar y explicar a la gente cómo era que las guerrillas se daban plomo entre sí. Teníamos, desde 2002 mucho cansancio de combate. Además la arrogancia de las FARC nos debilitaba como insurgencia y todo, porque nosotros, en esa vorágine, terminamos por parecernos a ellos. Nos arrastraron los mismos errores. Estábamos en descomposición interna y empezamos con una operatividad poco limpia, a criminalizarnos y perdimos parte de nuestra naturaleza. Era guerra perdida, sobre todo cuando se consolida la presencia de las Fuerzas Militares y las AUC. Ellos a nosotros no nos dieron mucho en el combate directo pero le dieron muy duro a la población. Salimos bien frente al Bloque Magdalena Medio y del paramilitarismo previo, de los ochenta, que ya estaba por la región, pero nos debilitó la desaparición de nuestras bases. En definitiva, perdimos la guerra. Las AUC nos ganaron. Perdimos la guerra política y militar”. (Entrevista personal, junio de 2015).

En semejante línea se aprecia el testimonio de "Karina" cuando, al ser preguntada por esta cuestión reconocía que:

"Desde el año 2000, por la intensidad de las acciones de las AUC contra el ELN (en el oriente antioqueño) la guerrilla no va a poder hacer nada y va a desaparecer sin mayor resistencia". (Entrevista personal, mayo de 2015).

Algo similar va a suceder en la región norte del país, con motivo del impacto del Bloque Norte de las AUC, el bloque paramilitar más poderoso, y que va a estar detrás del activismo guerrillero en esta región, especialmente en Cesar y La Guajira. Igualmente serían consabidas las afectaciones en Barrancabermeja, donde se desarticula el importante Frente Urbano Resistencia Yariquíes, respecto del cual el paramilitarismo va a tener una responsabilidad nuclear. Baste recordar las significativas palabras del líder paramilitar "Don Berna", quien llegó a asegurar que, por aquel entonces, cerca 2.000 combatientes del ELN abandonaron la guerrilla para engrosar las filas de las AUC. ${ }^{55}$

Toda esta repercusión en la estructura guerrillera del ELN va a tener lugar, sin embargo, en escenarios bien de índole urbana, bien en escenarios en los que la principal seña de ingresos para la guerrilla proviene del secuestro y la extorsión y no del cultivo ilícito. Es decir, si se observa el mapa anterior se puede dar cuenta de qué modo, entre 2001 y 2012 se aprecia una desaparición del activismo guerrillero en la mayoría de los enclaves descritos, pero no en Norte de Santander y Arauca en el nororiente, y en el corredor Pacífico de los departamentos de Chocó, Cauca y Nariño, en el suroccidente.

\footnotetext{
55 Aponte, David: "Terminando el conflicto violento con el ELN: de la necesidad de finalizarlo más allá del recurso de las armas", en Aponte, David y Vargas, Andrés (eds.) (2011): No estamos condenados a la guerra. Hacia una estrategia de cierre del conflicto con el ELN, Bogotá, CINEP, pp. 32-110.
} 
De los siete departamentos con presencia de la guerrilla, cinco son de índole fronteriza y, a su vez, escenarios nucleares en el cultivo de coca. Tanto, que solo en Norte de Santander, Cauca, Chocó y Nariño, para los años 2011 y 2012, se registró una superficie cultivada que ascendió a las $52.301 \mathrm{Ha}$, o lo que es igual, el $47 \%$ del total de cultivos del país ${ }^{56}$. La salvedad la representaría el departamento de Arauca, un departamento de tradicional presencia del ELN pero en el que predominan, más que los cultivos ilícitos, las prácticas de extractivismo y contrabando 57 .

La capacidad de arraigo de esta guerrilla sobre los dos escenarios más importantes para su activismo guerrillero se puede entender con lo siguiente. Entre 2011 y 2012 el ELN protagoniza 20 acciones guerrilleras, en unos términos similares a los de una década atrás y aun cuando solo en este departamento fueron el objetivo de un total de 452 operativos militares. Más evidente es, si cabe, el caso de Arauca, donde entre 2011 y 2012 protagonizaron hasta 54 acciones guerrilleras, casi en los niveles más altos de activismo de los últimos quince años, y a pesar de recibir 179 combates unilaterales. Por su parte, en la vertiente del Pacífico (Chocó-Cauca-Nariño) entre 2011 y 2012 se habrían contabilizado hasta 37 acciones guerrilleras, en unos registros estables con el acumulado a lo largo de la década, y a pesar de haberse puesto en marcha hasta 397 operativos militares.

Si de visibilizar y operacionalizar la hipótesis de la narcotización se trata, se debe integrar el indicador de presencia municipal con el indicador de presencia de cultivos de coca. Es decir, tener en cuenta en cuántos municipios se registró al menos una acción armada del ELN entre $2001^{58}$ y 2012 , y en cuantos concurre la presencia de hectáreas cultivadas de coca. Así, y como se puede observar en el siguiente gráfico, si la presencia municipal del ELN a inicios de la década pasada, ascendía a 131 municipios de los cuales solo 31 presentaban cultivos ilícitos, once años después, si bien es cierto que su presencia territorial ha decaído un $76 \%$, al quedarse en 31 municipios, de igual forma se ha incrementado sustancialmente la proporción con enclaves cocaleros, pues del total de estos 31 municipios, 18 presentan hectáreas con cultivos de coca.

\footnotetext{
${ }^{56}$ Véase UNODC: “Colombia. Monitoreo de cultivos de coca 2012” (junio 2013), en https://www.unodc.org/documents/cropmonitoring/Colombia/Colombia Monitoreo de Cultivos de Coca 2012 web.pdf

${ }^{57}$ Basta recoger las palabras del exdirigente del ELN, "Felipe Torres" cuando reconoce: "En otro contexto, como en Arauca, el ELN siempre fue hegemónico. Impidió la llegada de los paramilitares, y le dio plomo a los Frentes 28, 10 y 45 de las FARC, evitando que la presencia de cultivos fuese dominantes. Esto se dio por la fuerza del frente Domingo Laín y su control sobre la frontera. Esto es muy importante porque de los 5.000 millones de dólares que pasan por la frontera colombiana a modo de contrabando, en los departamentos de Arauca, La Guajira, Cesar, Norte de Santander y Vichada, una tercera parte, pasa por Arauca y la mitad de su control, lo tiene el ELN. A este ingreso hay que añadir el control sobre la construcción de obras, incluso civiles, en las que para su concesión la guerrilla se beneficia gravando hasta un $10 \%$ del valor de la obra. Es lo que vulgarmente se conoce como el "CVY", es decir - y señala entre risas- el "cómo voy yo". (Entrevista personal, mayo de 2015).

${ }^{58}$ El año 2001 es el primero del cual hay reportes de UNODC sobre cultivo ilícito
} 


\section{Gráfico 2: Presencia armada del ELN en relación a los municipios con presencia de cultivos ilícitos, 1998 - 2012}

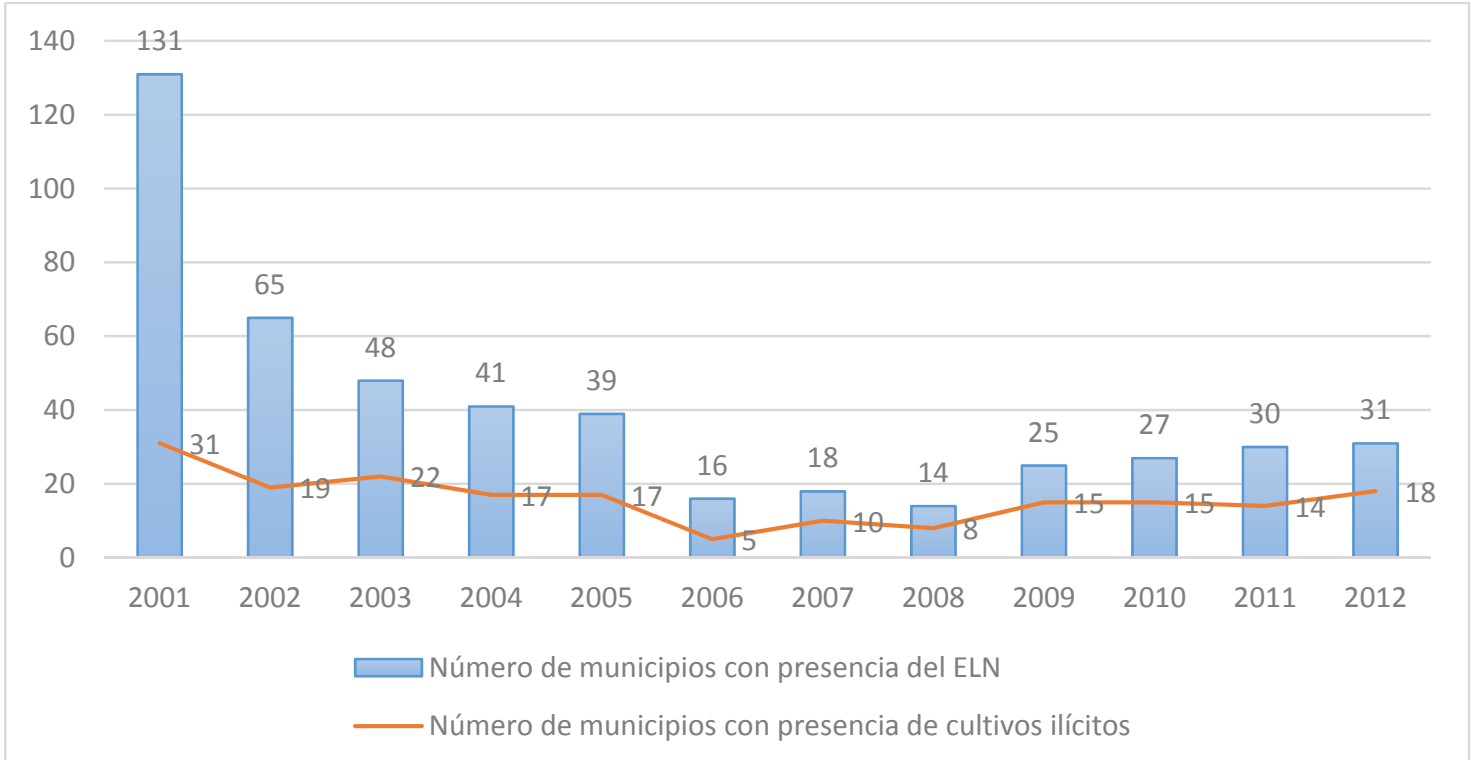

Fuente: Elaboración propia con base en los datos del ODHDIH y UNODC.

Es decir, los municipios en los que tradicionalmente se ha encontrado el ELN con presencia de cultivos ilícitos, esto es, primero en Antioquia, Norte de Santander y Arauca, y después, sustituyendo el primero de estos, por un mayor activismo en el Pacífico, han sido municipios donde su presencia, de mayor modo, se ha mantenido inalterada cuando no creciente en el período que transcurre entre 2001 y 2012. Dicho de otro modo, cabe pensar en que los cultivos ilícitos son una fuente importante de mantenimiento y supervivencia del grupo, de manera tal que allí donde se intersecta la variable ELN - cultivo ilícito, hay mayores posibilidades de continuidad del activismo guerrillero, dada su importancia como fuente de poder económico.

Departamentos como Huila, Tolima y el eje cafetero, en la región central, o Cesar, Sucre y La Guajira en la costa atlántica, así como el departamento de Santander, nunca presentaron cultivos ilícitos o, en su defecto, la magnitud de los mismos siempre fue muy reducida, de manera tal que el ELN, en el momento en el que interactúa con el resto de actores, rápidamente es expulsado de estos enclaves. De igual manera, esta hipótesis ayuda a interpretar por qué Norte de Santander, Antioquia o el Pacífico han sido, y continúan siendo, escenarios con arraigo del ELN y con alta presencia cocalera, lo cual también se observa cuando se utiliza como indicador de medición, no la presencia municipal, sino el activismo guerrillero.

De este modo, no solo se refuerza la hipótesis planteada, sino que se hace más evidente, pues, tal y como se puede apreciar igualmente en el siguiente gráfico 3 , las acciones del ELN sobre municipios con presencia de cultivos ilícitos hoy en día es muy similar a la cifra que se registraba en 2002 o en 2003, cuando la fuerza del grupo guerrillero y su presencia territorial se encontraba en el cénit de los últimos cuarenta años. 
Gráfico 3: Acciones armadas del ELN sobre escenarios con presencia de cultivos ilícitos 1998 - 2012

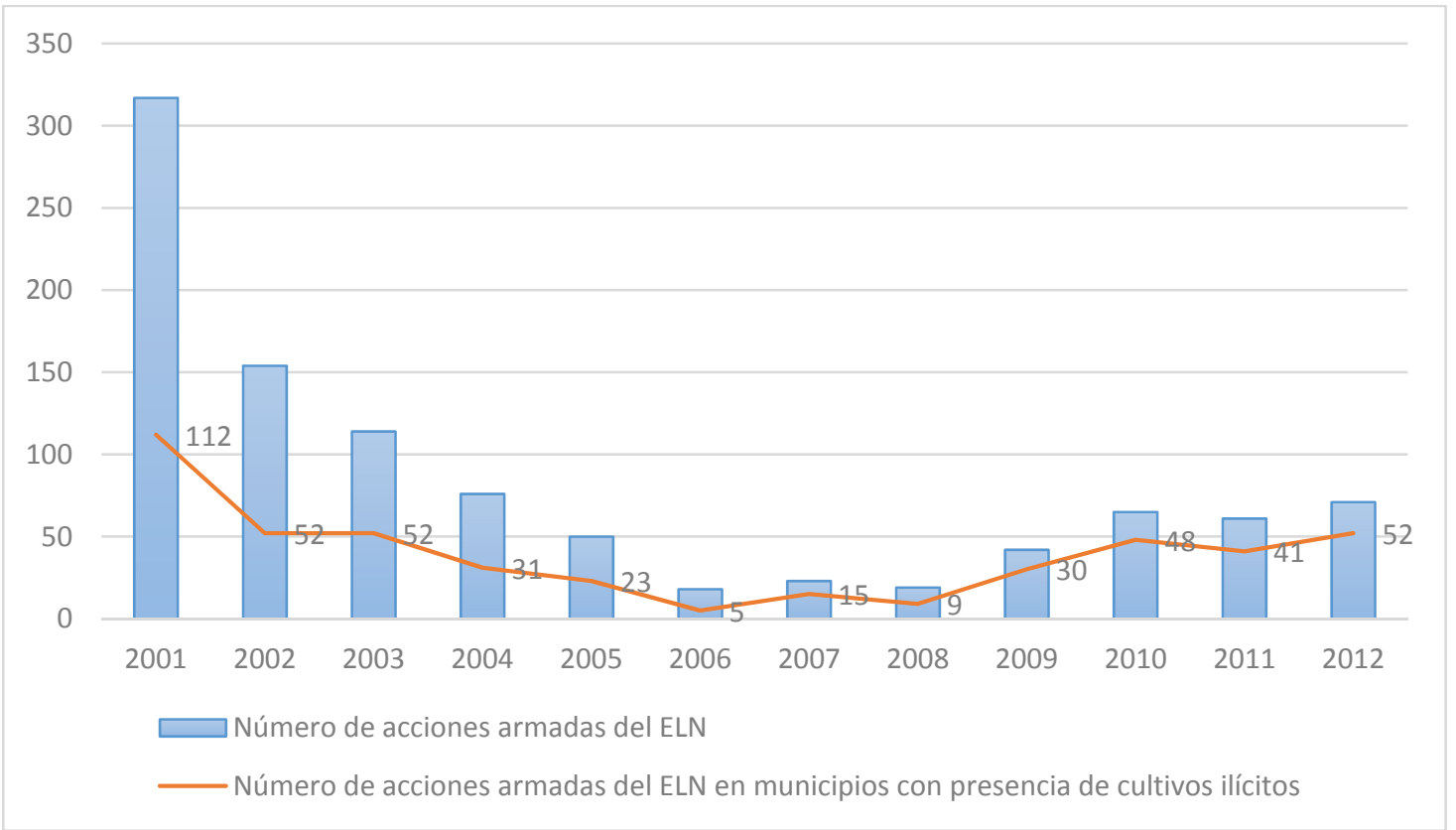

Fuente: Elaboración propia con base en los datos del ODHDIH y de UNODC.

Lo que sucedería es que, bajo esta apreciación, se pone de manifiesto una focalización creciente del activismo guerrillero del ELN sobre enclaves con presencia de cultivos, pudiendo observarse la concentración de acciones armadas en aquellos municipios con existencia de cultivos ilícitos. Es decir, se aprecia una relación que responde a una tendencia constante, estable y significativa, especialmente, a partir de 2009, una vez que se pone fin a la situación de arrinconamiento e invisibilización que experimenta la guerrilla, especialmente, entre los años 2006 y 2009.

Es ilustrativo, a tal efecto, comparar las diferencias que transcurren entre los años 2002 y 2012. Es decir, como se señalaba con anterioridad, con un similar número de acciones armadas sobre municipios con presencia de cultivos de coca, alrededor de la media centena, en el año 2002 la acción guerrillera del ELN mayormente tenía lugar en enclaves sin presencia de cultivos ilícitos, lo cual cambia drásticamente en lo que se puede observar diez años después.

Con el paso de los años, entre 2001 y 2012, se hace más evidente que, para la subsistencia de la guerrilla, la financiación y los recursos económicos que facilitan los cultivos ilícitos, se han erigido como un rubro indisociable a su existencia. Buena prueba de ello es que casi tres cuartas partes de las acciones armadas del ELN tienen lugar en escenarios cocaleros, lo cual significa más de treinta puntos porcentuales con respecto a la situación que se daba hace una década. 
Gráfico 4: Relación porcentual entre las acciones armadas y la presencia municipal del ELN sobre escenarios con presencia de cultivos ilícitos, 2001 - 2012

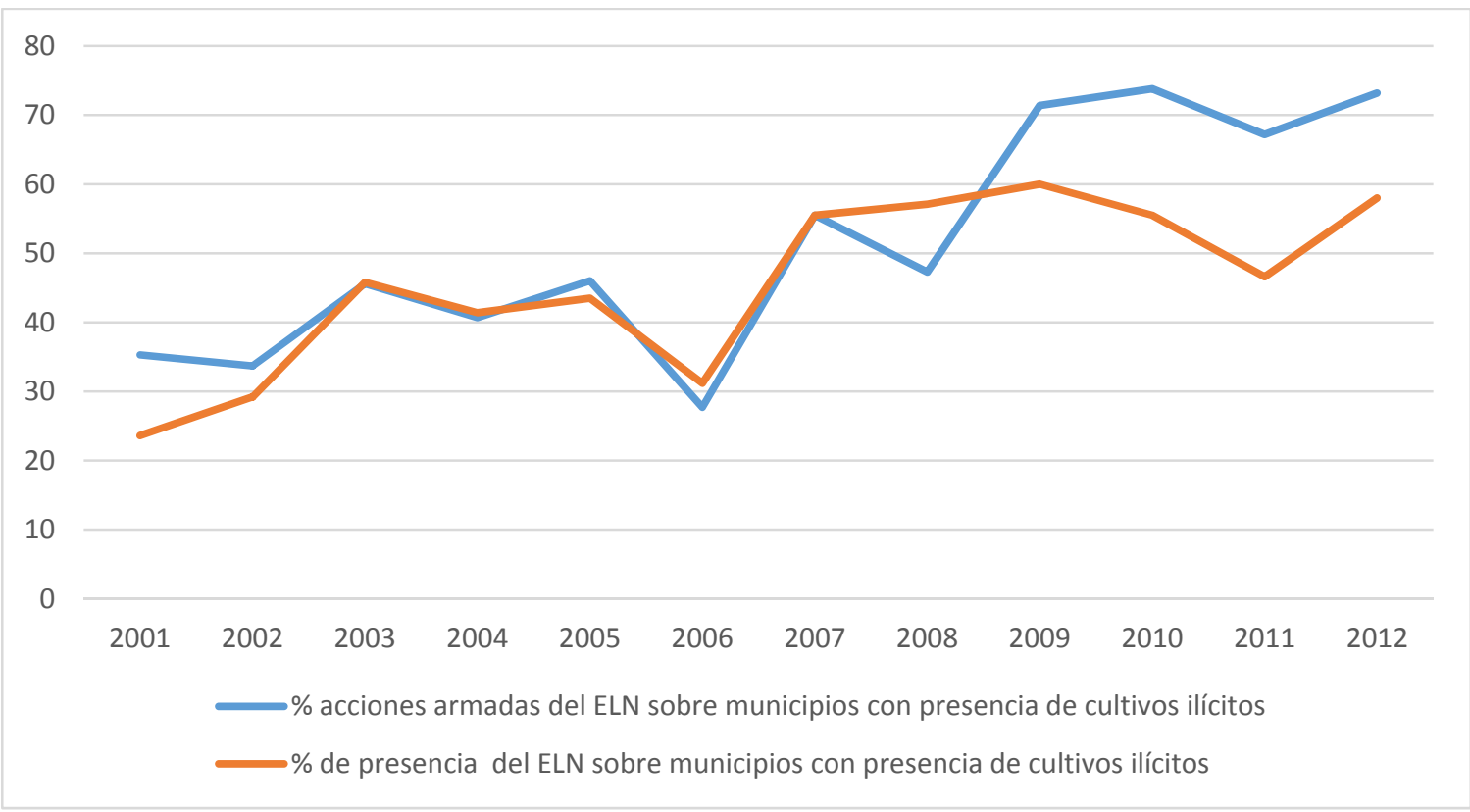

Fuente: Elaboración propia con base en los datos del ODHDIH y UNODC.

Finalmente, y de acuerdo a lo que se expone en el gráfico 4, se terminaría por redundar en la hipótesis planteada. Si en 2001 los municipios con presencia de cultivos ilícitos sobre los que se evidenciaba presencia del ELN era de un $23.6 \%$, tras un proceso creciente e incremental, en 2012, el mismo indicador asciende a un 58.0\%. Más si cabe resulta reveladora la cifra de las acciones armadas. Si éstas se concentraban, para el caso del ELN, en un 35.3\% en municipios con presencia de cultivo ilícito, ese porcentaje ascendía hasta el $73.2 \%$, una década después.

Con esto, y en conclusión, parecería que los cambios y transformaciones del conflicto armado colombiano en los últimos años, y particularmente en su relación con el ELN, han terminado por poner de manifiesto qué importantes resultan los cultivos ilícitos, tanto para entender la supervivencia guerrillera al impacto del paramilitarismo y de la política de seguridad, por un lado, y para comprender las dinámicas territoriales de la violencia guerrillera en cuanto a su proximidad con respecto de enclaves productores de cultivos ilícitos, por otro.

\section{Resultados: La narcotización de las FARC entre 1998 y 2012}

A diferencia de lo que acontecía con el ELN, que entre 1998 y 2012 fue acumulando dificultades que estuvieron a punto de hacer desaparecer a la guerrilla, las FARC, si bien han perdido la mitad de su pie de fuerza y buena parte de su poder territorial, sin embargo, esto no se ha traducido, en términos generales, en lo que afecta a su activismo armado. Un activismo que todavía, y como se observó para el año 2012, supera las 800 acciones guerrilleras anuales, muy alejadas de las 65 del ELN.

Del modo que plantea en la siguiente tabla, y a pesar de que la presencia departamental es una tercera parte menos que en los mejores momentos de la guerrilla, su presencia municipal sigue afectando a casi 200 municipios del país, en unos términos 
similares a los de inicios de la década pasada, y con base en una tendencia expansiva que acontece desde 2008, además, mucho más visible respecto de lo que se destacaba para el ELN. En ese año 2008, tras cinco años de impacto de la Política de Seguridad Democrática, y trascurridos los mayores años de disputa con el paramilitarismo de las AUC, cuando la presencia municipal de las FARC cae a los 131 municipios, cifra que, sin embargo, ha ido paulatinamente creciendo en casi una tercera parte, hasta los 190 registrados en 2012.

Tabla 2: Evolución municipal y departamental de la presencia de las FARC entre 1998 y 2012

\begin{tabular}{|l|l|l|l|l|l|l|l|l|l|l|l|l|l|l|l|}
\hline & $\mathbf{1 9 9 8}$ & $\mathbf{1 9 9 9}$ & $\mathbf{2 0 0 0}$ & $\mathbf{2 0 0 1}$ & $\mathbf{2 0 0 2}$ & $\mathbf{2 0 0 3}$ & $\mathbf{2 0 0 4}$ & $\mathbf{2 0 0 5}$ & $\mathbf{2 0 0 6}$ & $\mathbf{2 0 0 7}$ & $\mathbf{2 0 0 8}$ & $\mathbf{2 0 0 9}$ & $\mathbf{2 0 1 0}$ & $\mathbf{2 0 1 1}$ & $\mathbf{2 0 1 2}$ \\
\hline $\begin{array}{l}\text { Municipios con } \\
\text { presencia de } \\
\text { FARC }\end{array}$ & 186 & 194 & 208 & 206 & 346 & 313 & 218 & 234 & 234 & 152 & 131 & 164 & 166 & 180 & 190 \\
\hline $\begin{array}{l}\text { Departamentos } \\
\text { con presencia } \\
\text { de FARC }\end{array}$ & 25 & 27 & 29 & 26 & 28 & 31 & 29 & 29 & 29 & 22 & 24 & 24 & 21 & 23 & 20 \\
\hline
\end{tabular}

Fuente: Elaboración propia con base en los datos del ODHDIH (2014) y UNODC (2014)

Si se observa el siguiente mapa 3, la evolución de la geografía de las FARC hacia el año 2012, y en comparación con 2002, pone de manifiesto un proceso de pérdida de fuerza paulatina, muy considerable, en dos enclaves. Por un lado, la región central, conformada por Cundinamarca, Boyacá y el eje cafetero; y por otro lado, la región Atlántica.

En la primera de ellas hay un gran impacto de una política de seguridad que rompe con la estrategia envolvente de la guerrilla sobre Bogotá. ${ }^{59}$ Basta con destacar, por ejemplo, Operativos como Libertad I, en 2003, en la que participaron más de 15.000 efectivos dentro de un campo de acción de más de $70.000 \mathrm{~km}^{2}$, abarcando el oriente de Tolima, todo el departamento de Cundinamarca, el norte de Meta y el suroriente de Boyacá. Asimismo, en Cundinamarca, solo entre 2002 y 2003, se desarrollan 357 operativos militares sobre las FARC que hacen que si en el mismo 2002, las acciones de las FARC seguían presentando unos niveles de violencia considerables (129), en 2005 ya no se computa ni una sola acción guerrillera. Igual sucede en el mencionado eje cafetero donde entre 2002 y 2007, con 238 acciones militares en Caldas, 65 en Quindío y 86 en Risaralda, las FARC son expulsadas. Incluso, en Boyacá, en donde había acciones guerrilleras desde los años ochenta por la confluencia de los Frentes 28, 10 y 45, se ponen en marcha hasta 141 acciones militares que hace que en 2007, por primera vez en décadas, no haya constancia de una sola acción protagonizada por las FARC.

\footnotetext{
${ }^{59}$ Entre los años 2000 y 2002, sobre todo, las FARC buscan obtener una ventaja militar dentro del conflicto armado buscando una estrategia envolvente, de asfixia sobre Bogotá que, sin embargo, resulta insostenible de manera que para 2004 prácticamente han quedado replegadas, no solo alrededor de la ciudad, sino de todo el departamento de Cundinamarca.
} 


\section{Mapa 3: Cartografía del activismo armado del ELN en el año 2000 y en 2012}
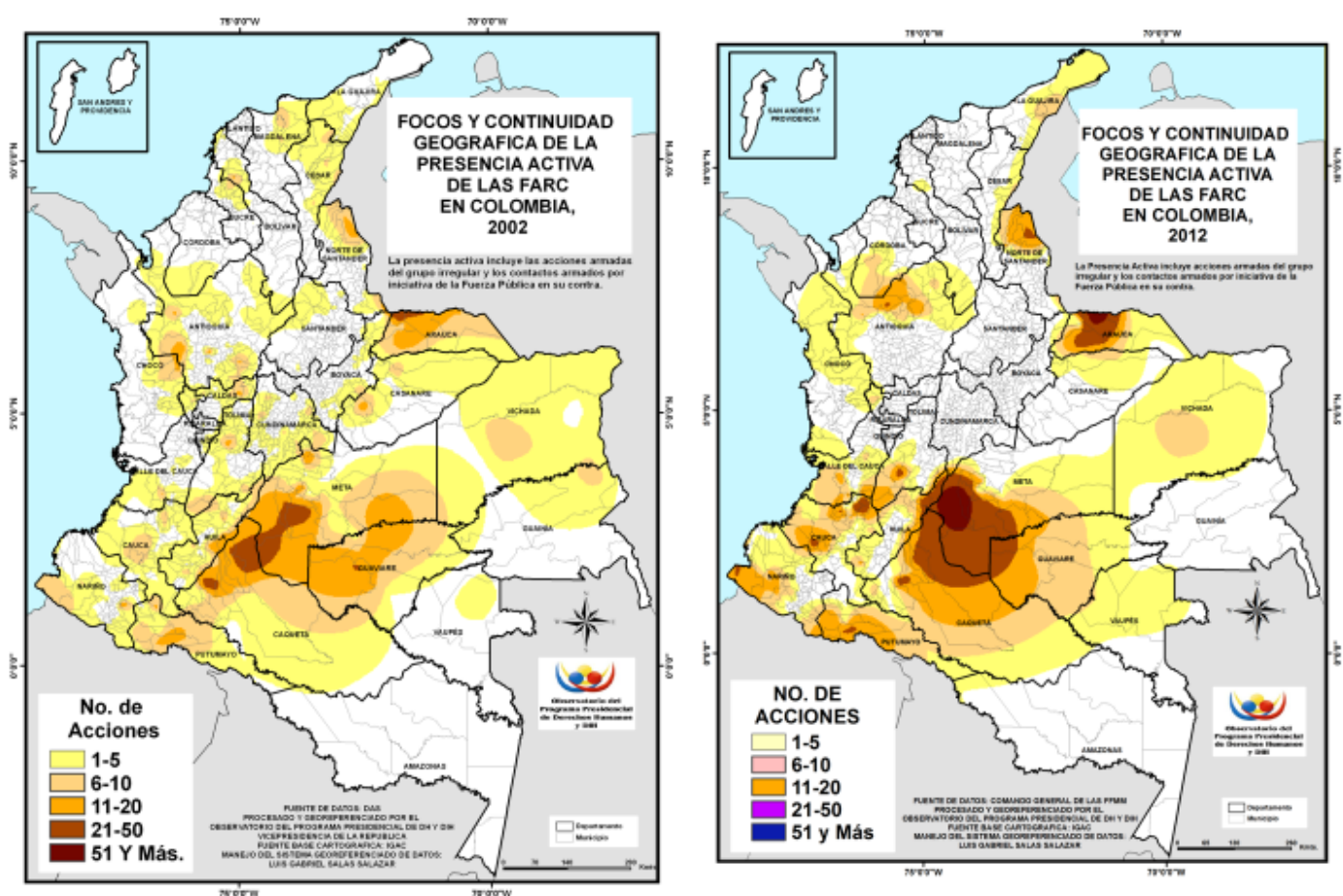

Fuente: ODHDIH

Igual de evidente será en la costa atlántica. En el departamento de Atlántico, de gran impronta paramilitar, la presencia guerrillera de las FARC siempre resultó muy reducida como también sucedía en el departamento paramilitar por antonomasia: Córdoba. Sin embargo, entre 2002 y 2007 se aprecia una muy significativa reducción del activismo guerrillero, en tanto que terminan por desaparecer en 2007 de Magdalena, Sucre y Cesar, y se mantienen, aunque con dificultades, en La Guajira y Bolívar. De hecho, solo en los tres departamentos se contabilizan en estos seis años hasta un total de 232 acciones militares en Cesar, 215 en Magdalena y 219 en Sucre. En contraste, y en suma en los tres departamentos, las FARC protagonizan 245 acciones guerrilleras, lo que evidencia la notable disparidad de fuerzas. A lo anterior habría que sumar la concurrencia, en este particular escenario del país, del poderoso Bloque Norte de las AUC, especialmente activo entre 1998 y 2005 en estos siete departamentos del país. Un Bloque Norte que, muy especialmente, controla social y militarmente los departamentos de Atlántico, Magdalena, La Guajira y Cesar, de tal modo que en muchos enclaves se erigió como actor hegemónico, sobre todo, una vez que es derrotado el competidor paramilitar creado bajo la sombra de Hernán Giraldo Serna.

Una prueba de su magnitud es el hecho de que solo entre 1998 y 2005 se le atribuyen hasta 82 masacres y 598 víctimas mortales, siendo las localidades más azotadas por su violencia Barrancas, Dibulla, Distracción, Hato Nuevo, Maicao, Maricazo, Villanueva, Riohacha, Urumita y San Juan del Cesar, en La Guajira; Arataca, Ariguani, Ciénaga, El Piñón, Fundación, Pivijay, Pueblo Viejo, Santa Marta, Sitio Nuevo, Zona Bananera, en Magdalena; Barranquilla, Luruaco, Malambo y Soledad en Atlántico y, finalmente, Agustín Codazzi, Astrea, Becerril, Curumaní y Valledupar, en Cesar. Buena parte de estos enclaves de activismo guerrillero de los Frentes 19, 35, 37, 41 y 59 de las FARC, quedaron profundamente afectados en lo que "Karina" definió del siguiente modo: 
"Las AUC frenaron nuestro avance y atacó a la población civil. Todos eran susceptibles de apoyar a la guerrilla, fuese real o no. y en esas, nosotros acabamos haciendo lo mismo. Excediéndonos y dando de baja al que era susceptible de ser informante paramilitar. Las AUC hacían valer el dicho de quitar el agua al pez para asfixiarlo. Y así nos hicieron mucho daño". (Entrevista personal, mayo de 2015)

No por casualidad, y frente a lo anterior, hay tres escenarios que resultan nucleares para la subsistencia de la guerrilla y que, en el fondo, no se han visto alterados, más allá de altibajos propios de la coyuntura, en el activismo acontecido en los últimos años. En primer lugar, estaría el nororiente del país, en torno a los departamentos de Arauca y Norte de Santander, donde las FARC comparten presencia con el ELN. En Norte de Santander, porque para ambas guerrillas, la región del Catatumbo cuenta con unas condiciones particulares especiales. Es una región selvática, fronteriza con Venezuela y de alto valor como corredor estratégico. Asimismo, porque se trata de uno de los grandes enclaves cocaleros del país, pues solo entre 2011 y 2012 se cultivaron $2.340 \mathrm{Ha}$ en Tibú, 926Ha en Teorama, $1.848 \mathrm{Ha}$ en Sardinata, 976Ha en El Tarra y 536Ha en Convención, donde asimismo, en total, se concentran hasta 65 acciones guerrilleras, es decir, la práctica totalidad de las acciones de las FARC en el departamento. En Arauca, porque el departamento ha sido un enclave tradicional de presencia del frente 10, que por muchos años le disputó la hegemonía al frente "Domingo Laín" del ELN.

En segundo lugar, estaría el corredor amazónico formado por los departamentos de Meta, Caquetá y Putumayo. Un corredor que desde décadas ha sido controlado por las FARC. Eso, porque aunque entre 2002 y 2012 se han dirigido 1.502 combates contra esta guerrilla en el departamento de Caquetá, 2.573 combates en Meta y 602 en Putumayo, en diciembre de 2012, que es hasta donde llega el marco de estudio, en los tres departamentos se registraban más acciones armadas de parte de la guerrilla que operativos de la Fuerza Pública. Es decir, lejos de lo que se pudiera pensar, la política de confrontación directa con las guerrillas no se ha traducido, como en otros enclaves en una derrota militar de las FARC. La geografía selvática y la concurrencia de cultivos ilícitos, especialmente en Caquetá y Putumayo, donde el $100 \%$ de las acciones de las FARC se dan sobre enclaves cocaleros - que entre 2011 y 2012 supusieron la nada desdeñable cifra de casi $30.000 \mathrm{Ha}$ cultivadas.

Por último, y de acuerdo a una dinámica creciente, mucho más notoria e importante que la también llevada a cabo por el ELN, se encontraría la región del Pacífico, fundamentalmente Cauca y Nariño, y en menor medida, pero también relevante, Chocó y los departamentos de interior en la región suroccidental de Tolima y Huila que, a su vez, fungen de conexión estratégica directa con Cauca y Nariño. 
Gráfico 6: Presencia armada de las FARC en relación a los municipios con presencia de cultivos ilícitos, 2001 - 2012

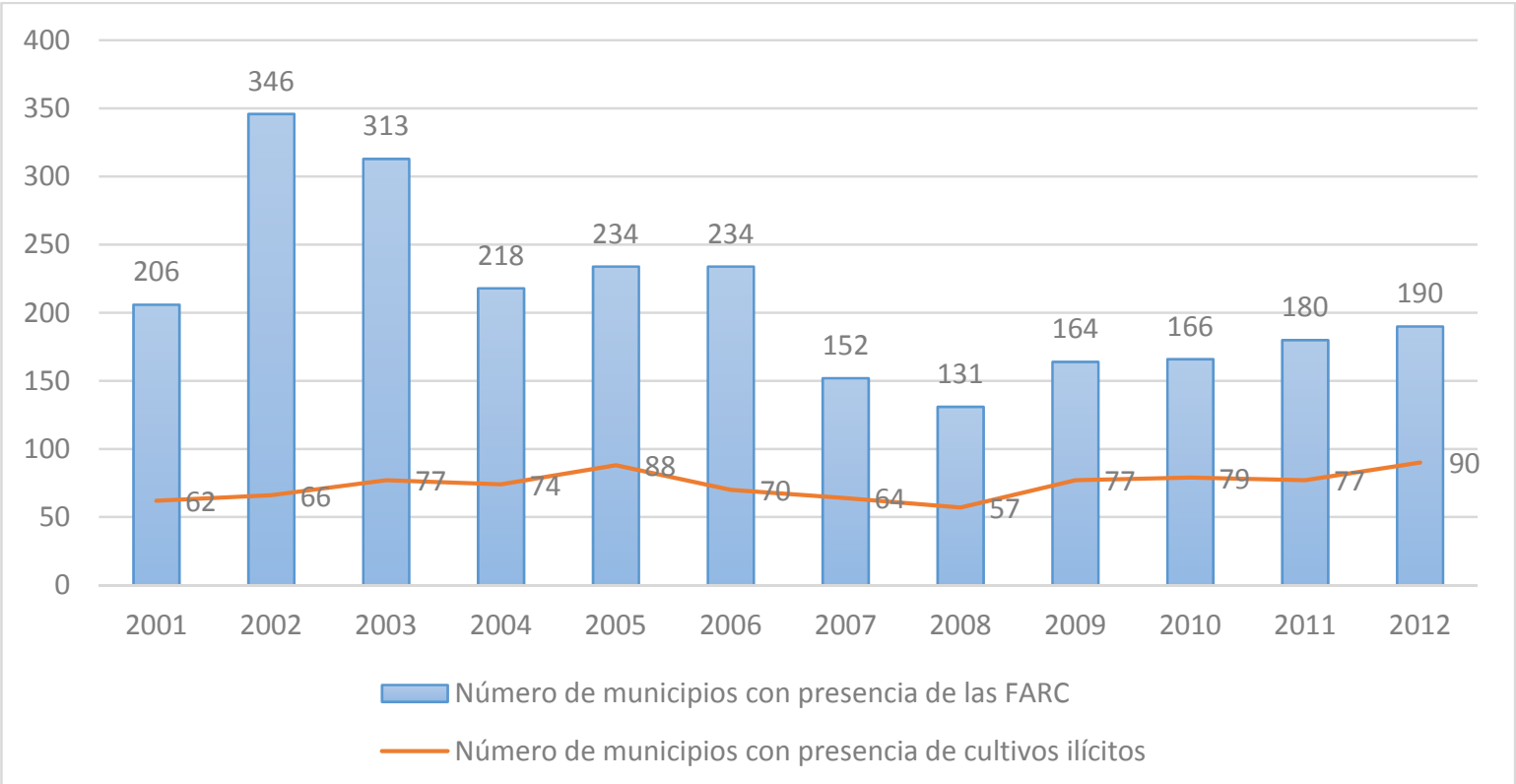

Fuente: Elaboración propia con base en los datos del ODHDIH (2014) y UNODC (2014)

Nuevamente, se encuentra lo que fue una prioridad para los gobiernos, sobre todo, de Andrés Pastrana y Álvaro Uribe, a la vez que una continuidad, inalterada, en los niveles de activismo guerrillero. Durante la década que transcurre entre 2002 y 2012 contabilizan un total de 1.132 combates unilaterales de la Fuerza Pública en Cauca, 544 en Nariño, 895 en Tolima y 620 en Huila. Sin embargo, se aprecia que los niveles de violencia guerrillera no se reducen y, de hecho, tanto en Tolima con en Huila se mantienes niveles estables con respecto a una década, en torno a las 40 acciones anuales, toda que se aprecia una correlación de fuerzas favorable tanto en Cauca como en Nariño, donde las acciones, entre 2011 y 2012 ascienden 305 y 150 respectivamente y se condensan en los enclaves cocaleros que acumulan por encima de las $38.000 \mathrm{Ha}$ de superficie cultivada.

Sea como fuere, lo cierto es que el proceso de desnaturalización de la guerrilla no es comparable al experimentado por el ELN, como se señalaba, especialmente, por el abandono de Santander y en Antioquia. En el caso de las FARC el nororiente siempre sirvió de retaguardia estratégica, toda vez que el corredor amazónico había sido su tradicional enclave de dominación. Un enclave, no obstante, en el cual, paulatinamente, sí que se aprecia una movilidad hacia el suroccidente del país, específicamente sobre un Pacífico colombiano que si hace años era un enclave de retaguardia, hoy, respecto del eje Cauca-Nariño, se ha terminado por consolidar, de largo, como el principal bastión armado y territorial de las FARC.

El abandono de la región del Atlántico, ha sido notorio en Sucre, Bolívar y Cesar, más que en otros departamentos como La Guajira, donde ha habido una reactivación del Frente 59, entre 2011 y 2012, que sin embargo, no se puede aún valorar estrictamente en términos de recomposición real de la guerrilla. Lo mismo se puede señalar para el caso de Antioquia. De lo que no hay duda es que los tres enclaves prioritarios para las FARC como son el nororiente, el suroccidente y el eje Meta-Caquetá-Putumayo presentan un alto valor agregado en términos estratégicos, al concurrir hasta seis departamentos fronterizos, y una notable presencia de cultivos que confiere sostenibilidad a la prolongación del conflicto. Baste que en estos 
departamentos de la cuenca del Pacífico, Norte de Santander y el eje Meta-Caquetá-Putumayo se acumulaba en 2012 el $78 \%$ de los cultivos de coca presentes en el país. ${ }^{60}$

De acuerdo con el gráfico 6, si se observa el año 2001, que es cuando comienza el análisis del factor del cultivo ilícito en los informes de UNODC, se puede dar cuenta que sobre un total de 206 municipios con activismo de las FARC, en 62 había concurrencia de cultivos ilícitos. Transcurridos once años, y con un número similar de municipios con presencia de FARC a los de entonces (190), el número de municipios con presencia de cultivos adicional, se ha incrementado en más de un 50\%, siempre en los departamentos ya planteados.

\section{Gráfico 7: Acciones armadas de las FARC sobre escenarios con presencia de cultivos ilícitos, 1998 - 2012}

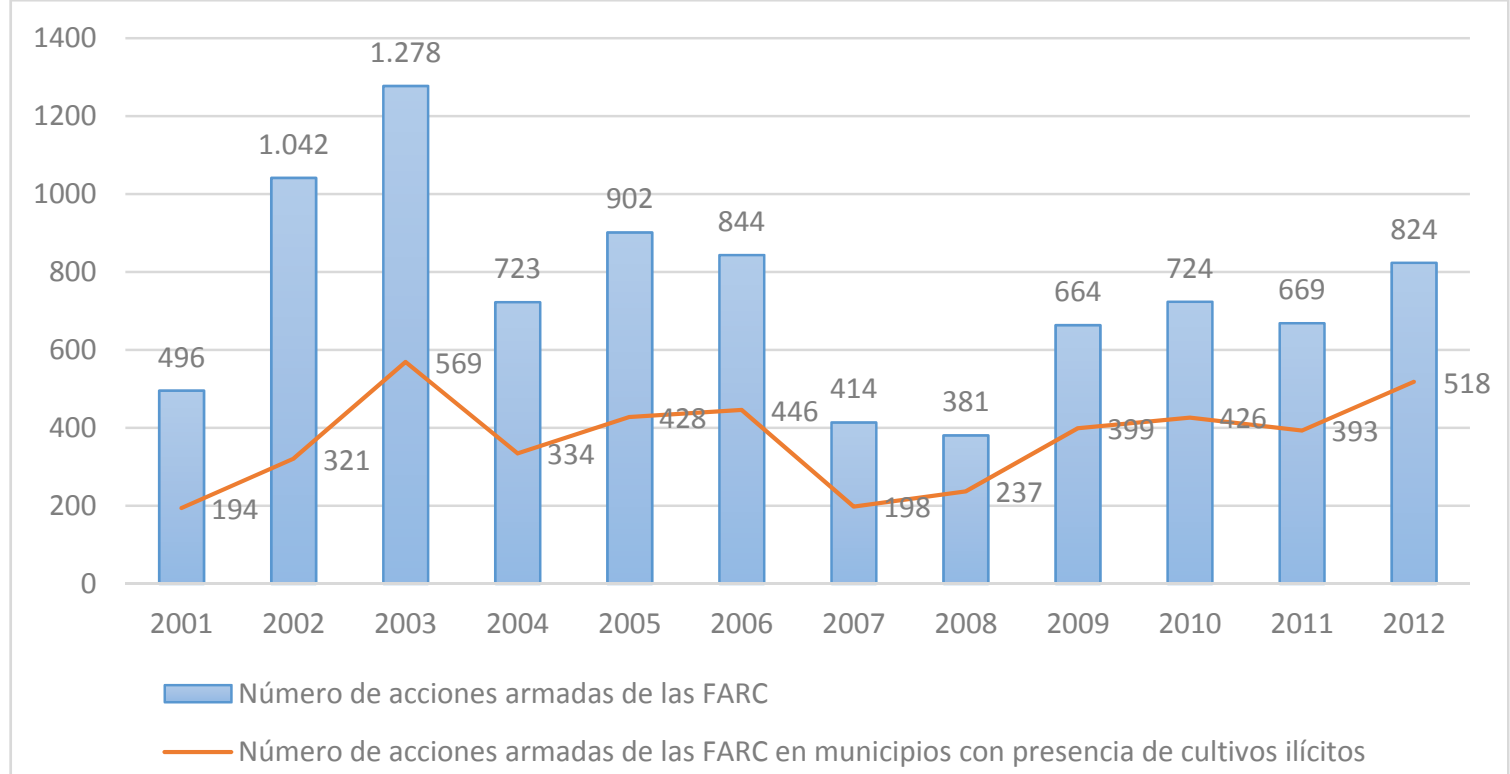

Fuente: Elaboración propia con base en los datos del ODHDIH y UNODC

Es decir, en buena medida, explicado por la desaparición de las FARC de la región central y septentrional, y su consolidación en los enclaves de mayor presencia cocalera, la cual permite entender de mejor modo la tesis de la continuidad de la lucha guerrillera así como la financiación de la misma.

Al igual que como sucedía con el ELN, si se toma como valor las acciones armadas que se presentan en el gráfico anterior, se redunda en la hipótesis que se planteaba al inicio de este trabajo. Es decir, si en 2001 sobre un total de 496 acciones de las FARC 194 acciones armadas tenían lugar sobre municipios con presencia de cultivo, dicha proporción aumenta significativamente una década después. Ello, porque para el año 2012, sobre un total de 824 acciones guerrilleras, 518 se han desarrollado sobre escenarios con presencia cocalera. Es más, en este año 2012 se condensó el segundo mayor número de acciones armadas sobre municipios con cultivos ilícitos, pues las 518 acciones referidas solo resultaron superadas en el transcurso de la década pasada, por las 569 del año 2003. El año de mayor fuerza de la historia de las FARC, si bien, en aquel momento el activismo sobre cultivos ilícitos se dio sobre un total de casi 1.300 acciones guerrilleras.

\footnotetext{
${ }^{60}$ En 2012, el desglose porcentual de cultivos de coca por una superficie cultivada de $48.000 \mathrm{Ha}$ fue el siguiente: Nariño (22\%), Putumayo (13\%), Norte de Santander (9\%), Cauca (9\%), Caquetá (8\%), Chocó (7\%), Antioquia $(6 \%)$ y Meta $(4 \%)$.
} 
Igualmente, se puede apreciar que, el número de intensificación guerrillera viene acumulando una mayor presencia sobre enclaves cocaleros desde el año 2008, la cual se acompaña de una mayor intensidad armada y, como se veía anteriormente, de una mayor presencia territorial, que bien puede entenderse en términos de la proximidad a los réditos económicos que favorecen los cultivos ilícitos.

Gráfico 8: Relación porcentual entre las acciones armadas y la presencia municipal de las FARC sobre escenarios con presencia de cultivos ilícitos, 1998 - 2012

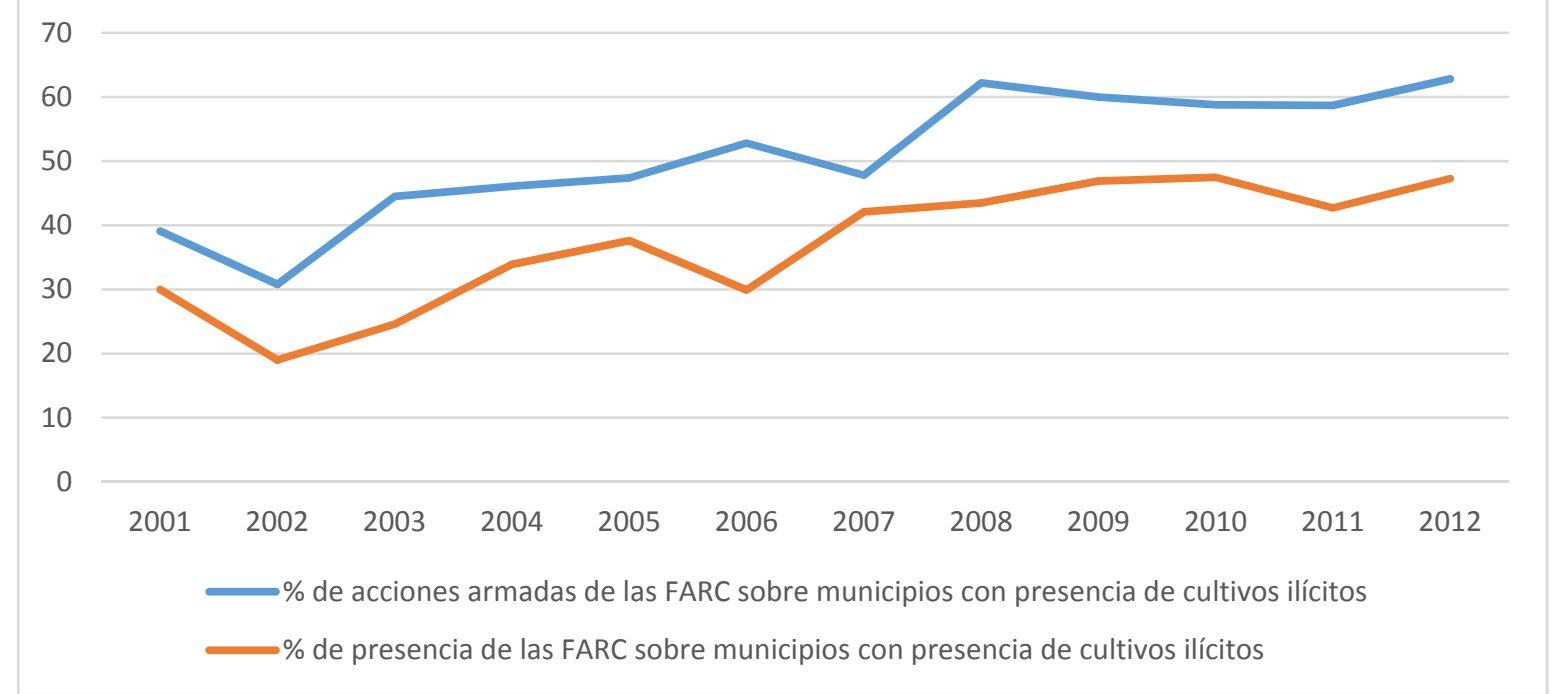

Fuente: Elaboración propia con base en los datos del ODHDIH y UNODC.

Planteado de otro modo, si en 2001 o en 2002, la presencia de las FARC a nivel municipal, apenas afectaba a un $30 \%$ y un $19 \%$ de municipios con presencia de cultivos ilícitos, esa proporción asciende, de manera creciente, a lo largo de toda la década pasada para llegar, en 2012, a niveles de casi el 50\%. Por tanto, se aprecia una lógica similar a la planteada en el epígrafe anterior con el ELN y que, de igual forma, se hace mucho más evidente con el medidor que suponen las acciones armadas. Así, para el año 2001 y 2002, la proporción de acciones guerrilleras sobre municipios con presencia de cultivos era de un $39.1 \%$ y un $30 \%$ respectivamente. Una proporción que casi se duplica, con el transcurso de los años, al llegar al $62.8 \%$, siendo la proporción más elevada en la relación activismo armado/presencia de cultivos ilícitos, de la historia reciente de las FARC.

\section{Conclusiones}

Con base en lo expuesto a lo largo de este trabajo es que se puede apreciar cómo FARC y ELN han concentrado sus acciones armadas y su presencia municipal sobre enclaves con fuerte influencia en cuanto a presencia de cultivos ilícitos en los últimos quince años transcurridos entre 1998 y 2012. En el caso de las FARC, su activismo armado se ha condensado en Arauca y Norte de Santander, en el nororiente y en toda la región suroccidental - sur de Tolima, Huila, Cauca y Nariño, además de en el tradicional corredor que conecta, hacia el sur, Meta, Caquetá y Putumayo. Estos departamentos, con la excepción de Nariño y Norte de Santander, desde hace dos décadas han sido enclaves de notable presencia guerrillera, de tal manera que cabe, cuando menos cuestionar, el alcance de las políticas de seguridad transcurridas hasta el momento con miras a una derrota por la vía militar de las guerrillas. Además, todos estos departamentos tienen conexión directa con el narcotráfico, bien como enclaves productores, bien como corredores estratégicos. Está por ver, por otro lado, que sucede en Antioquia, pues si bien las guerrillas se habían replegado en 
la segunda mitad de la década pasada, parecen haber cobrado nuevamente fuerza en el departamento.

Lo mismo sucedería con el ELN, cuyo activismo se ha consolidado en Arauca y Norte de Santander, así como en Chocó, Cauca y Nariño, en la vertiente del Pacífico. Igual proceso de adaptación sobre enclaves fronterizos a la vez que cocaleros. Algo, que en principio el ELN siempre ha negado si bien, más allá de la concordancia cartográfica, no se pueden dejar de lado las palabras que, a tal efecto, se recogían del comandante "Felipe Torres" o, por ejemplo, de un personero de la región del Catatumbo, en Norte de Santander, quien señalaba que a:

"El cultivo ilícito es el que explica la mayor parte de la presencia de los grupos armados en el Catatumbo. Se nos disparan estos cultivos desde el año 2006, incluso en la cabecera municipal urbana, lo cual antes nunca había sucedido. Ya sabe que este municipio es de los que más hoja de coca tiene del país lo cual nos condena a una presencia de grupos guerrilleros, que son los que controlan todo el cultivo. Ellos tienen todo el mercado bajo su dominio. Las tres guerrillas, FARC, ELN y EPL ${ }^{61}$ controlan la coca." (Entrevista personal, mayo de 2015).

Además de lo anterior, tanto en el caso de FARC como de ELN, aun con las diferentes tendencias experimentadas en los últimos quince años, de expansión en cuanto a los niveles de violencia, entre 1998 y 2001-02, de repliegue, entre 2002 y 2007-08, y nuevamente de expansión, desde 2009 y hasta 2012, se puede apreciar que buena parte de los escenarios de mayor intensidad han sido los mismos. Escenarios en los que, cuando menos, se puede aceptar la posibilidad de que los cultivos ilícitos, dominantes en todos los enclaves de mayor activismo, con la excepción particular de Arauca, han permitido nutrir de recursos a las guerrillas a efectos de continuar las lógicas de confrontación propias del conflicto armado. Confrontaciones que desnaturalizan a las guerrillas, por "narcotizar" el espíritu que las albergó en los años sesenta y que dificultan el conflicto en la medida en que estos escenarios, son más complejos en su geografía, tanto para la continuidad del activismo guerrillero como para el despliegue de operativos en favor de la Fuerza Pública.

Una segunda conclusión, conectada con lo anterior, sería el cuestionamiento al paradigma de la seguridad y a la política de confrontación que ha dominado en Colombia entre 1998 y 2012. Tras aproximadamente 15.000 millones de dólares invertidos en seguridad y defensa, 3.300 combates unilaterales por parte de la Fuerza Pública contra el ELN y otros 17.312 contra las FARC, y a pesar de haberse reducido sustancialmente el pie de fuerza de las guerrillas y su control territorial, el conflicto no se ha resuelto militarmente en aquellos departamentos en los que, tradicionalmente, hubo un mayor arraigo guerrillero y un mayor apego al negocio del narcotráfico. Dicho de otro modo, dos de cada tres acciones guerrilleras que tienen lugar en Colombia, lo hacen sobre enclaves con presencia cocalera, lo cual equivale a un $50 \%$ más de lo que tenía lugar hace una década. A tal efecto, además, deben cuestionarse las políticas reactivas contra el cultivo ilícito, basadas fundamentalmente en las cuestionadas aspersiones con glifosato.

\footnotetext{
${ }^{61}$ El Ejército Popular de Liberación es una guerrilla minoritaria, de corte maoísta, que en la actualidad cuenta con apenas 200 efectivos, que termina siendo un remanente de la guerrilla desmovilizada en 1990.
} 


\section{Mapa 4: Cartografía de la violencia guerrillera y la concurrencia de cultivos ilícitos}
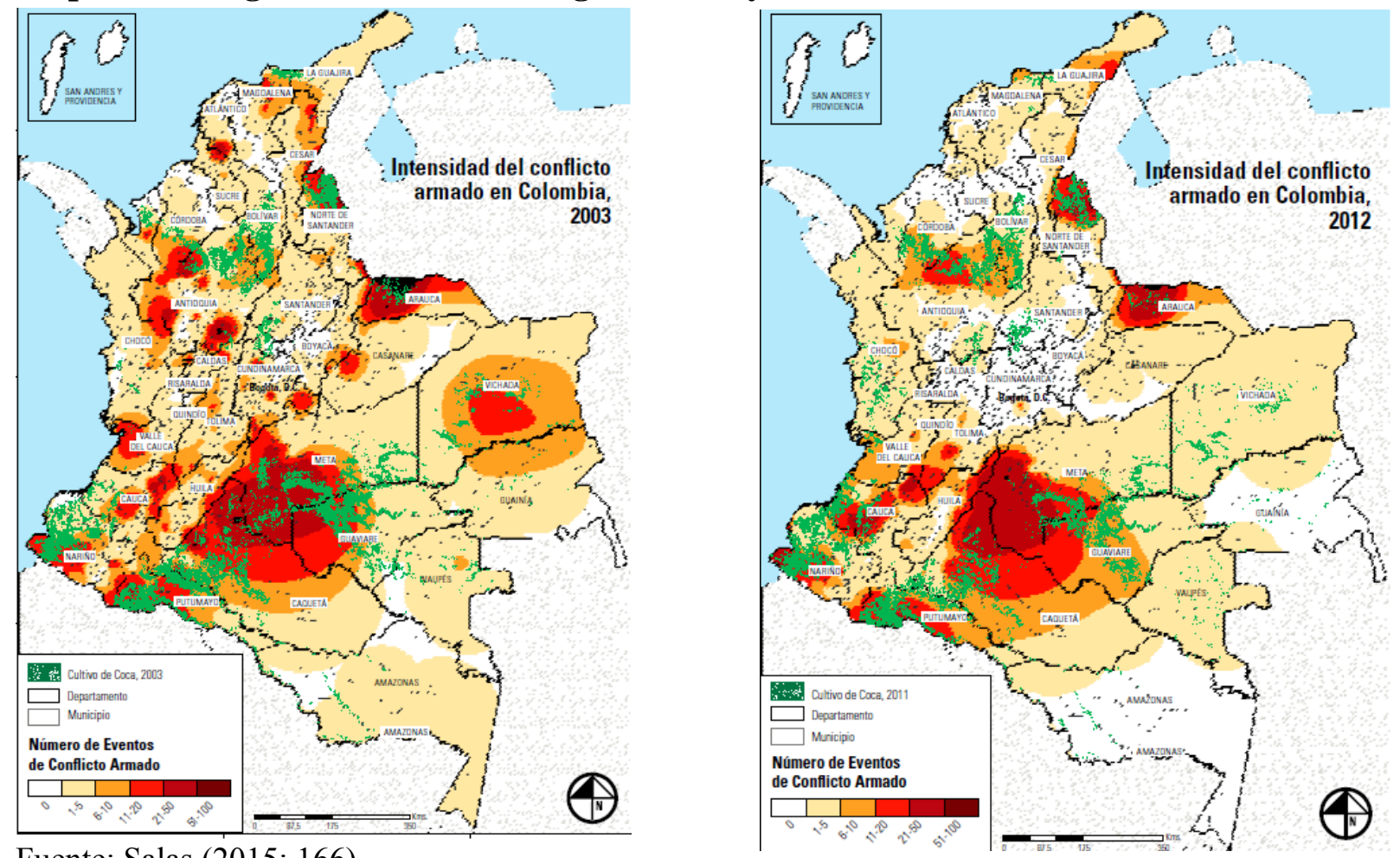

Fuente: Salas (2015: 166)

Las aspersiones aéreas con este fungicida, únicas en el mundo, fueron la llave nuclear del Plan Colombia, y la acción predominante entre 1998 y 2012. Sin, embargo tras más de un millón de hectáreas asperjadas, y aunque la superficie del cultivo ilícito se ha reducido de más de $150.000 \mathrm{Ha}$ en 1998 a 48.000Ha, departamentos como Antioquia, Cauca, Chocó, Nariño y Putumayo están en niveles estables con respecto a los registros de hace una década, incluso con tendencias crecientes, como muestra el crecimiento de la superficie cultivada, hasta casi $70.000 \mathrm{Ha}$, entre 2013 y 2014, nuevamente, en estos escenarios. Quizás, tras lo anterior, se entienda la decisión del gobierno, en el verano de 2015, de poner fin al empleo de las aspersiones como forma de combatir el cultivo ilícito en Colombia.

Una tercera conclusión podría ayudar a entender el actual marco de negociaciones que tiene lugar con las FARC en La Habana, Cuba, y el actual proceso de exploraciones previas a una negociación con el ELN. Haciendo válidas las palabras de Kissinger, "la guerrilla gana si

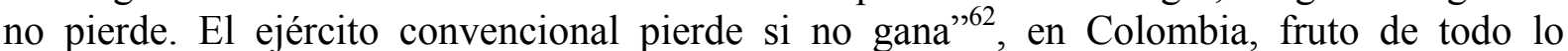
anterior, cabe pensar en una situación de "doble estancamiento doloroso", tal y como lo plantean autores como Touval y Zartman o Zartman, y por el cual, proseguir con las mismas dinámicas de violencia, sin negociar, termina por generar recíprocas consecuencias negativas, tanto para la guerrilla como para el gobierno ${ }^{63}$.

\footnotetext{
${ }^{62}$ Kissinger, Henry: "The Vietnam Negotiations”, Foreign Affairs, vol. 48, nº 2 (enero 1969), pp. 38-50.

${ }^{63}$ El concepto mutually hurting stalemate, se refiere a la situación que se da cuando las partes se encuentran ante una situación de conflicto cuya prolongación no ofrece posibilidades de victoria a ninguna de las partes y, por tanto, gana enteros la opción de negociar. Se destacan, respecto de este concepto los trabajos de Touval, Saadia y Zartman, William I. (1985): International Mediation in Theory and Practice, Boulder, Westview; Zartman, William I.: "The Unfinished Agenda. Negotiating Internal Conflicts", en Licklider, Roy (ed.) (1993): Stopping the Killing: How Civil Wars End, Nueva York, New York University Press, pp. 20-34; y Zartman, William I.: "The Timing of Peace Initiatives: Hurting Stalemates and Ripe Moments", The Global Review of Ethnopolitics, vol. $1, \mathrm{n}^{\mathrm{o}} 1$ (septiembre 2001), pp. 8-18.
} 
Esta situación acontece cuando las partes se hallan en una situación en las que el prolongamiento de la situación conflictiva no ofrece posibilidades de victoria a ninguna de las partes. Dicho de otro modo, en la actualidad, y tras los años de conflicto armado referidos, tiene lugar una situación en la que el Gobierno empieza a requerir ingentes esfuerzos económicos y militares para combatir a unas guerrillas cuya ubicación espacial termina siendo un valor agregado que, cuando menos, relativiza el alcance y éxito de los operativos orientados a su debilitamiento en estos enclaves. A su vez, para las guerrillas, la posición periférica le relega a una posición de presencia territorial mucho más difícil $\mathrm{y}$, dadas las circunstancias de disparidad de fuerzas, imposible de revertir. De esta manera, la convergencia de un diálogo cobraría más fuerza que nunca.

En cuarto lugar, y como posibles líneas expeditivas desde las que completar esta investigación, cabe apreciar que los enclaves referidos, en los que concurren mayor número de acciones guerrilleras y mayor presencia de coca, a su vez, se presentan elevadísimos niveles de violencia estructural. Por ejemplo, por Índice de Desarrollo Humano, Caquetá, Putumayo, Nariño, Norte de Santander y Cauca presentan niveles de desarrollo, inferiores a 0.78 y muy por debajo de la media nacional (0.804). Igualmente, atendiendo el Índice de Necesidades Básicas Insatisfechas, Chocó, Cauca, Arauca, Nariño, Caquetá y Norte de Santander, nuevamente superan el promedio nacional, con déficits en cuanto a necesidades públicas que afectan a más del $58 \%$ de su población. Esto es, todo invitaría a pensar en la necesidad de incorporar nuevas variables que añadan la dimensión estructural como factor explicativo de las dinámicas espaciales de ruptura y continuidad de la violencia, aunque a modo de sugerencia que complementen trabajos posteriores.

Sin embargo, y sea como fuere, lo que es evidente es que, como termina proponiendo este trabajo, la Geografía Política debe reivindicarse como una disciplina que, perfectamente, es susceptible de integrarse en la Investigación para la Paz y la Resolución de Conflictos. Un binomio, aún por explorar, y que encuentra en la actual coyuntura que presenta Colombia, un prolífico horizonte de estudio que arroje aportaciones concluyentes sobre la importancia del espacio y del lugar en la continuidad de la guerra así como en la construcción de la paz 